\title{
Theoretical Investigation on Single-Wall Carbon Nanotubes Doped with Nitrogen, Pyridine-Like Nitrogen Defects, and Transition Metal Atoms
}

\author{
Michael Mananghaya, ${ }^{1,2}$ Emmanuel Rodulfo, ${ }^{1}$ Gil Nonato Santos, ${ }^{1}$ \\ Al Rey Villagracia, ${ }^{1}$ and Alvin Noe Ladines ${ }^{1}$ \\ ${ }^{1}$ Physics Department, De La Salle University-Manila, Taft Avenue, 1004 Manila, Philippines \\ ${ }^{2}$ Physics Department, Mapúa Institute of Technology, Muralla Street, Intramuros, 1002 Manila, Philippines \\ Correspondence should be addressed to Michael Mananghaya, mike_mananghaya@yahoo.com
}

Received 25 August 2011; Accepted 30 December 2011

Academic Editor: Xuedong Bai

Copyright ( $) 2012$ Michael Mananghaya et al. This is an open access article distributed under the Creative Commons Attribution License, which permits unrestricted use, distribution, and reproduction in any medium, provided the original work is properly cited.

\begin{abstract}
This study addresses the inherent difficulty in synthesizing single-walled carbon nanotubes (SWCNTs) with uniform chirality and well-defined electronic properties through the introduction of dopants, topological defects, and intercalation of metals. Depending on the desired application, one can modify the electronic and magnetic properties of SWCNTs through an appropriate introduction of imperfections. This scheme broadens the application areas of SWCNTs. Under this motivation, we present our ongoing investigations of the following models: (i) $(10,0)$ and $(5,5)$ SWCNT doped with nitrogen $\left(\mathrm{CN}_{x} \mathrm{NT}\right),(\mathrm{ii})(10,0)$ and $(5$, 5) SWCNT with pyridine-like defects $\left(3 \mathrm{NV}-\mathrm{CN}_{x} \mathrm{NT}\right)$, (iii) $(10,0)$ SWCNT with porphyrine-like defects $\left(4 \mathrm{ND}-\mathrm{CN}_{x} \mathrm{NT}\right)$. Models (ii) and (iii) were chemically functionalized with 14 transition metals (TMs): Sc, Ti, V, Cr, Mn, Fe, Co, Ni, Cu, Zn, Pd, Ag, Pt and $\mathrm{Au}$. Using the spin-unrestricted density functional theory (DFT), stable configurations, deformations, formation and binding energies, the effects of the doping concentration of nitrogen, pyridine-like and porphyrine-like defects on the electronic properties were all examined. Results reveal that the electronic properties of SWCNTs show strong dependence on the concentration and configuration of nitrogen impurities, its defects, and the TMs adsorbed.
\end{abstract}

\section{Introduction}

Properties of single-walled carbon nanotubes (SWCNT) are defined by its diameter, length, chirality or twist and the nature of the wall. The distinctive properties of SWCNTs for example, their surface area, stiffness, strength and resilience have led to a wide range of technological applications in mechanical materials, optics and electronics. There is however an inherent difficulty in synthesizing SWCNTs with uniform chirality and well-defined electronic properties. The difficulty mentioned are resolved by a calibrated introduction of dopants and/or defects that modify the electronic properties of SWCNTs [1-6]. The introduction of these imperfections leads to the creation of new energy levels in the band gap with associated electronic states. Our continuing investigation of how various types of defects and impurities in SWCNTs resulted in the modification of the band structure which hopes to provide a crucial guidance in controlling the electronic and magnetic properties of SWCNTs and ultimately in the design of novel devices requiring specific properties of SWCNTs.

Studies indicate Nitrogen (N) doping is particularly attractive because it has roughly the same atomic radius as carbon $(\mathrm{C})$ atoms and the extra electrons from the nitrogen dopants are expected to make semiconducting nanotubes metallic. N-doped CNTs $\left(\mathrm{CN}_{x} \mathrm{NTs}\right)$ have been synthesized in various approaches by several groups [7-15]. Experimentally, synthesis of SWCNT bundles doped with $\mathrm{N}$ via an aerosol-assisted chemical vapor deposition (CVD) method was reported although $\mathrm{N}$ doping concentration is unknown [16], $\mathrm{N}$ dopants are substituted into the $\mathrm{C}$ network with and without vacancy formation. Electron energy loss and X-ray 
photoelectron spectroscopy measurements, indicated that porphyrine-like (labeled as 4ND) and pyridine-like defects (labeled as $3 \mathrm{NV}$ ) $[9,10]$ are formed in the sidewalls of SWCNTs [17-19] in coexistence which greatly enhances the reactivity compared with pure CNTs $[16,20-34]$. The modification of the electronic and magnetic properties of CNTs can also be achieved through chemical decoration of transition metals (TMs) [35-37], and this greatly expands the potential application areas of CNTs [24-29, 31-34, 38].

Currently comparing the experimental advances in the interactions between TMs and $\mathrm{CN}_{x} \mathrm{NTs}$, to our knowledge, there are only a few theoretical studies on this issue [39-42] such as (1) recent reports that the binding energy of $\mathrm{Ni}$ or $\mathrm{Pt}$ with the CNT is significantly improved in the presence of the $3 \mathrm{NV}$ defect in the CNT $[39,40]$; (2) theoretical investigations on SWCNT doped with 12 TM by Mananghaya [41]; and (3) a theoretical study on the stability of Fe-adsorbed $\mathrm{CN}_{x} \mathrm{NTs}$ with porphyrine-like defect through the bent-cluster model [43]. The following topics still need to be answered: (1) the effects of nitrogen and pyridine-like doping on CNTs atomic deformation, molecular orbital, electronic structures and properties; (2) the bonding nature between different TMs and the CNT with $3 \mathrm{NV}$ defect $\left(3 \mathrm{NV}-\mathrm{CN}_{x} \mathrm{NT}\right)$ and $4 \mathrm{ND}$ defect (4ND-CN ${ }_{x} \mathrm{NT}$ ); and (3) the effects of various TMs adsorptions on the electronic and magnetic properties of $3 \mathrm{NV}-\mathrm{CN}_{x} \mathrm{NT}$ and $4 \mathrm{ND}-\mathrm{CN}_{x} \mathrm{NT}$. Hence, the aim of this study is to provide a comprehensive investigation of the effects of nitrogen doping at various concentrations, pyridine-like doping, as well as the chemical functionalization by 14 different TMs ( $\mathrm{Sc}, \mathrm{Ti}, \mathrm{V}, \mathrm{Cr}, \mathrm{Mn}, \mathrm{Fe}, \mathrm{Co}, \mathrm{Ni}, \mathrm{Cu}, \mathrm{Zn}, \mathrm{Pd}$, $\mathrm{Ag}, \mathrm{Pt}$ and $\mathrm{Au})$ on a $(10,0)$ and $(5,5) \mathrm{CNT}$ with $3 \mathrm{NV}$ and $(10,0)$ CNT with 4 ND defect using the spin-polarized DFT calculations. Stable configurations, deformation, formation energies, effects of the doping concentration of nitrogen and pyridine-like defects were all examined based on the spinpolarized DFT. Moreover, calculations on the corresponding binding energies and effects of TMs adsorptions on the electronic and magnetic properties of the nanotubes were implemented. The interaction of magnetic atoms with the nanotubes could lead to half metallic systems which are of great interest in the design of spintronic devices as well as applications of nanomagnets.

\section{Methodology}

The electronic properties of nitrogenated SWCNTs were studied using first-principles density functional theory (DFT), Dmol ${ }^{3}$ code, available from Accelrys [44]. Each electronic wave function is expanded in a localized atomcentered basis set with each basis function defined numerically on a dense radial grid. For supercell geometries, spin-restricted calculations were carried out with a double numeric polarized (DNP) basis set available and the atomic cutoff set at $4.6 \AA$, along with gradient-corrected PerdewBurke-Ernzerhof (PBE) functional [45]. Scalar relativistic effects [46] were included via a local pseudopotential for allelectron calculations. Five and ten Monkhorst-Pack $k$-points [47] were used for the Brillouin zone integration along the axes of $(10,0)$ and $(5,5)$ nanotubes, respectively. Geometry optimizations with the Broyden-Fletcher-Goldfarb-Shanno (BFGS) algorithm were performed with convergence criterion of $0.005 \AA$ on displacement, and $10^{-5}$ a.u. on the total energy and electron density. A hexagonal lattice was used to simulate the SWCNTs, with a wall-to-wall distance of at least $10 \AA$, sufficient to avoid in-plane interactions between nanotubes in adjacent unit cells. The Fermi levels of the spinrestricted band structures and density of states (DOS) of (10, $0)$ and $(5,0)$ nanotubes were reset at the $0 \mathrm{eV}$ position. For $\mathrm{Dmol}^{3}$ code, the molecular orbital of periodic systems was computed using only the $\Gamma$-point. The isodensity surfaces of highest occupied molecular orbital (HOMO) were fixed at 0.02 e/a.u. ${ }^{3}$.

Calculations were performed with supercells of zigzag $(10,0)$ (see Figures $1(\mathrm{a})-1(\mathrm{~d}))$ and armchair $(5,5)$ SWCNTs (see Figures 2(a)-2(d)). The supercell length of the zigzag (120 atoms/cell) and armchair (100 atoms/cell) nanotubes are $a=12.78 \AA$ and $a=12.30 \AA$, respectively. Three types of modified nanotubes were considered: (i) direct substitution of nitrogen dopants into the carbon framework without a formation of vacancy at $1.67 \%$ (Figure 1(b)) for $(10,0)$ and at $2.0 \%$ (Figure $2(\mathrm{~b})$ ) for $(5,5)$. Doping density varies from 0.83 to $2.0 \%$. (ii) Substitution of nitrogen dopants with vacancy formation, by removing a central $\mathrm{C}$ atom among three hexagons and replacing the three surrounding $\mathrm{C}$ atoms with $3 \mathrm{~N}$ atoms $\left(3 \mathrm{NV}-\mathrm{CN}_{x} \mathrm{NT}\right)$ at $5.08 \%$ (Figure $1(\mathrm{c})$ ) for $(10,0)$ and at $6.12 \%$ (Figure $2(c))$ for $(5,5)$. Doping density varies from 2.52 to $6.12 \%$. (iii) Chemical functionalization of 14 different TMs (Sc, Ti, V, Cr, Mn, Fe, Co, Ni, Cu, Zn, Pd, $\mathrm{Ag}, \mathrm{Pt}$, and $\mathrm{Au}$ ) on $3 \mathrm{NV}-\mathrm{CN}_{x} \mathrm{NT}$ (see Figures $1(\mathrm{~d})$ and $2(\mathrm{~d})$ ).

Specifically, in the direct substitution of nitrogen dopants the impurities are on opposite sides of the tube. Although the interaction between the two impurities is weak, we will see that the resulting bands are not simply related to concentration of impurities, but also the way $\mathrm{N}$ is distributed in the unit cell. It is evident that, in order to have a realistic description of doped CNTs, a random distribution of impurities should be used. However, we suppose an ideal situation in which impurities are distributed in a periodic cell can provide useful insights on the doping effects in a less computationally expensive way.

\section{Results and Discussions}

3.1. Structural Parameters. Figures 1 and 2 show the relaxed geometries of $(10,0)$ and $(5,5)$ nanotubes, respectively, along with the distribution of the highest-occupied molecular orbital (HOMO) of $(10,0)$ and $(5,5)$ SWCNT. Pure $(10$, $0)$ and $(5,5)$ SWCNT with the diameter of 7.83 and $6.78 \AA$, respectively, was chosen in the present work. Generally, it is noted that the cylindrically pristine nanotube is deformed to an ellipsoidal shape upon doping. A deformation factor $(\delta)$ is defined as the ratio of the major axis to the minor axis of the nanotubes. The $\delta$ values for the various types of nitrogenation are listed in Table 1; for pyridine-like doping, a $(5,5)$ nanotube $(\delta \approx 1.3)$ suffers a larger deformation than 

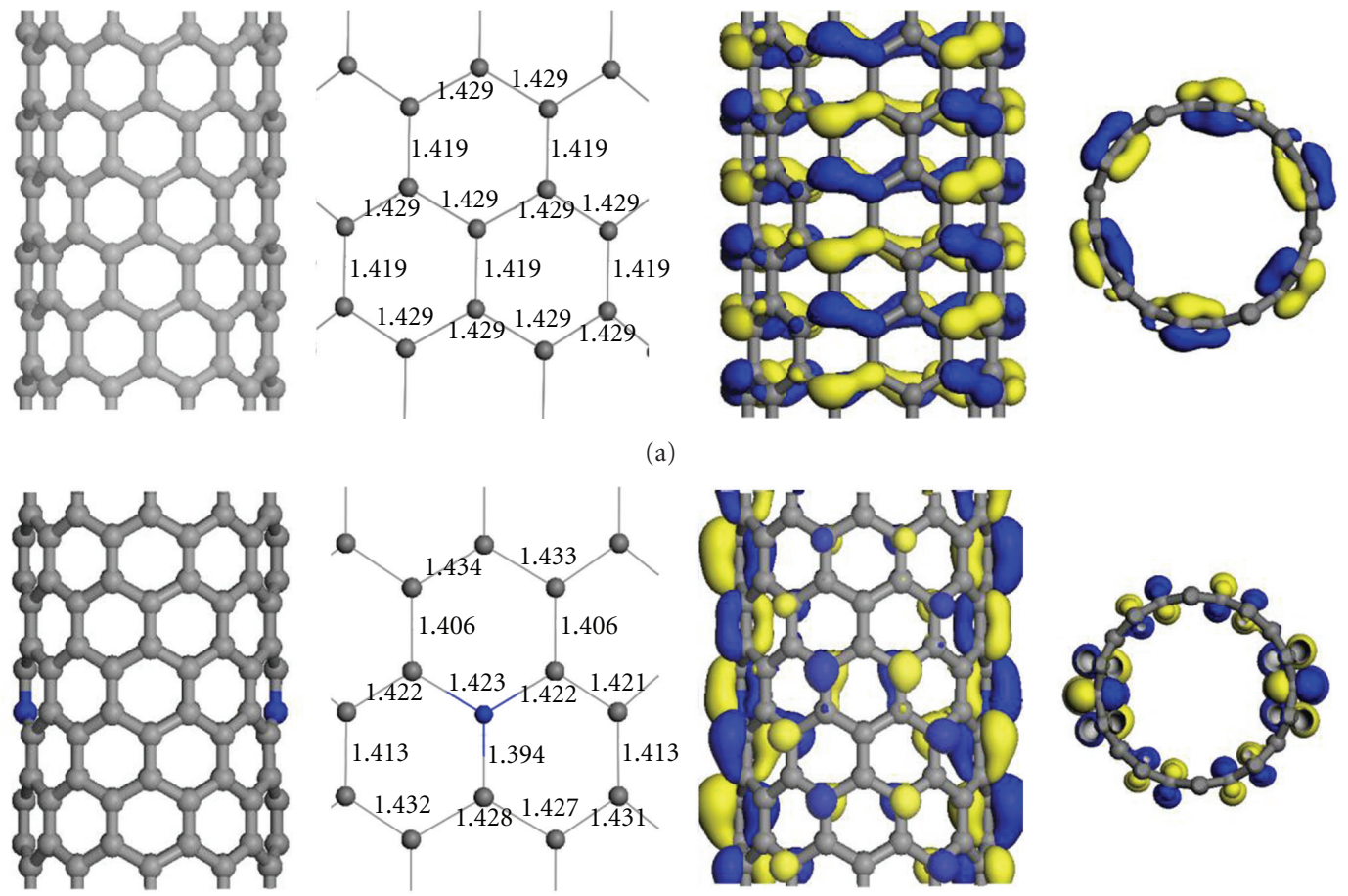

(b)
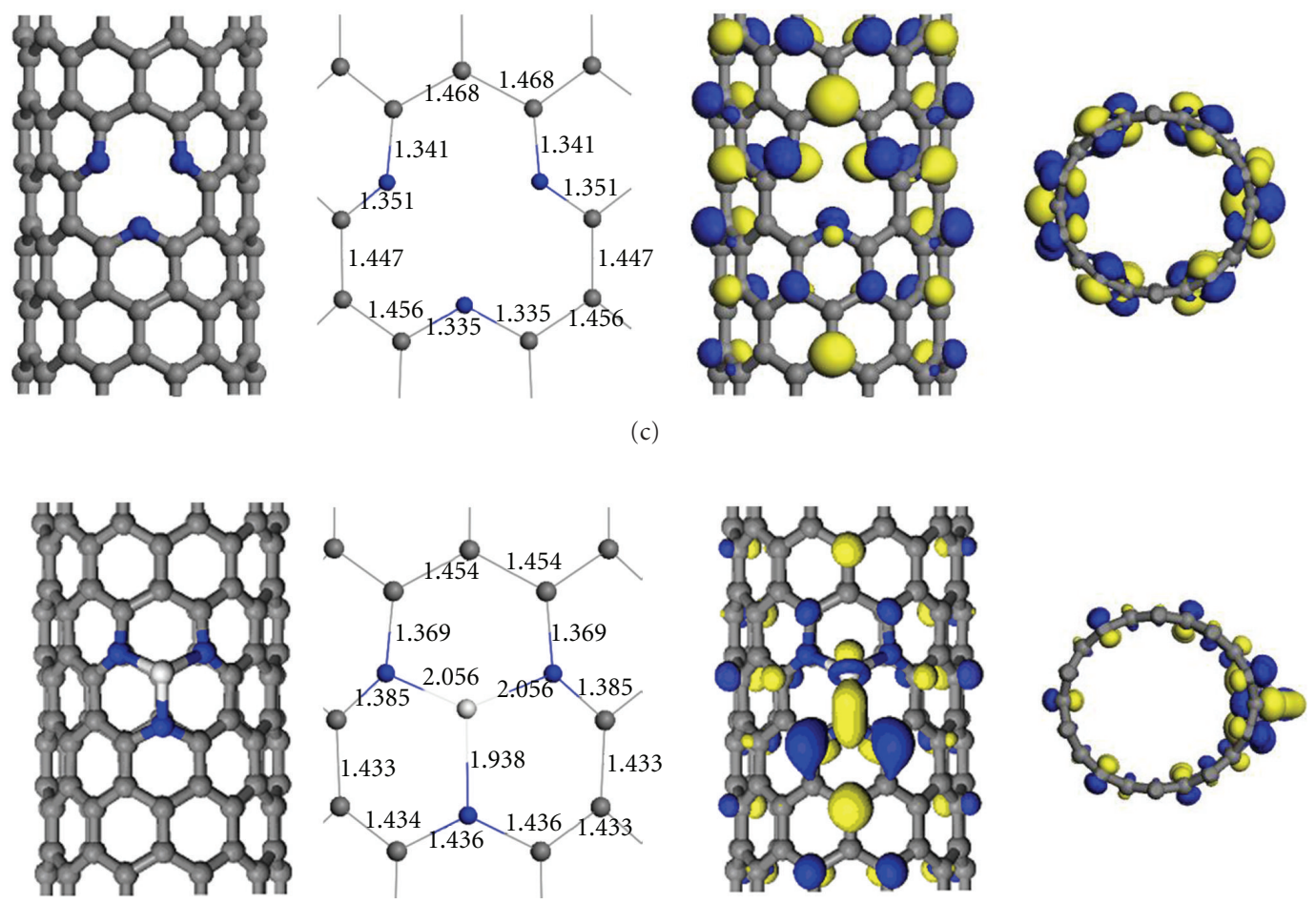

(d)

FIGURE 1: Geometrically optimized structures, bond lengths $(\AA)$, and highest occupied molecular orbital (HOMO) of (a) pure zigzag (10, 0 ) nanotube; (b) direct substitution of two nitrogen atoms into the carbon framework wherein the two $\mathrm{N}$ substitution atoms in $\mathrm{C}_{118} \mathrm{~N}_{2}$ are in the opposite positions; (c) N substitution into the carbon framework with the formation of pyridine-like vacancy: pyridine-like doping $\mathrm{C}_{112} \mathrm{~N}_{6}$ wherein two vacancies are formed in opposite positions; (d) adsorption configuration of the transition metal on a nanotube with pyridine-like defect. Grey ball denotes $\mathrm{C}$ atom, blue ball denotes N atom, and white denotes TM (Sc). A fragment of the supercell was taken out to elucidate the bond lengths at the vicinity of the impurities. 

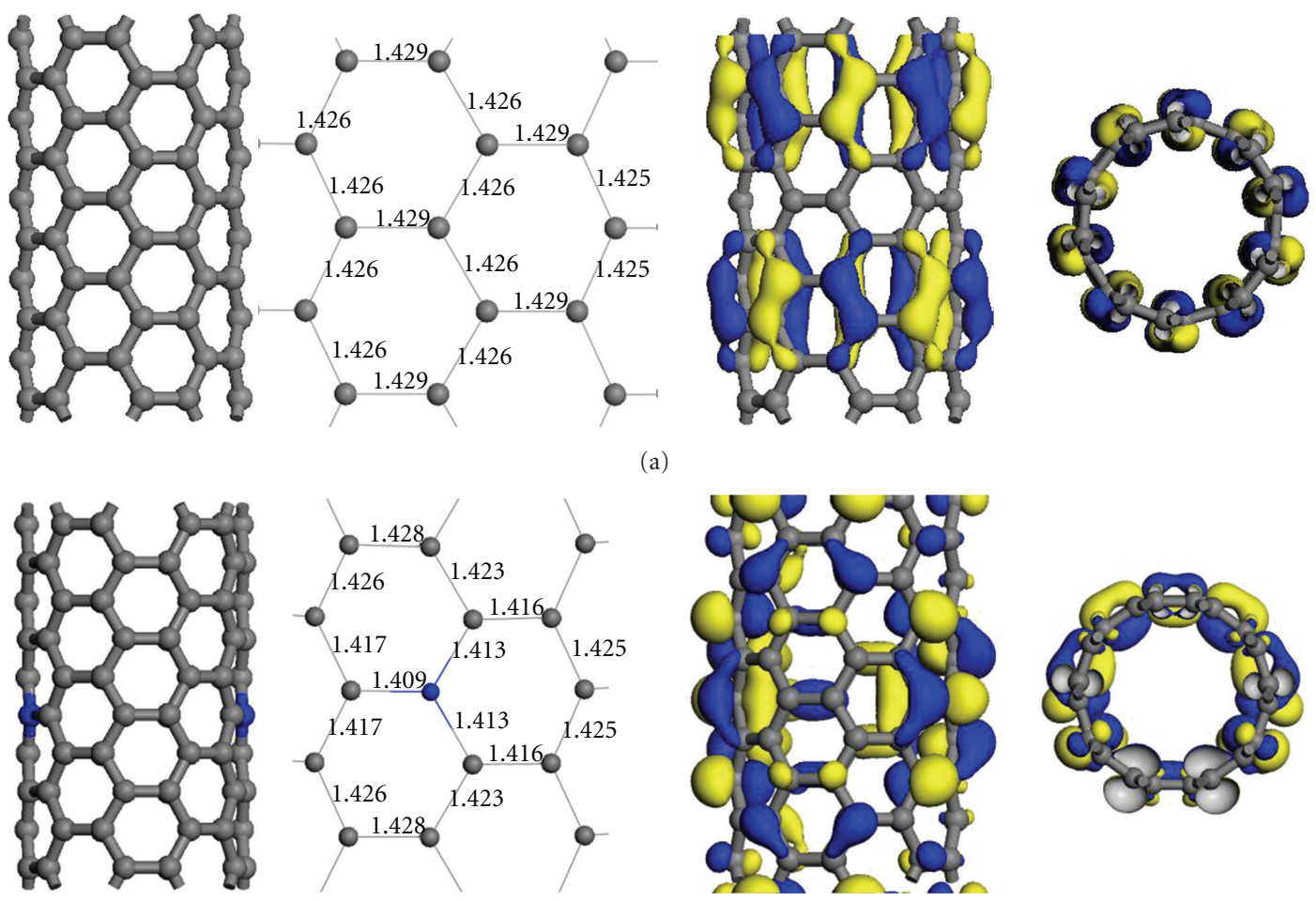

(a)
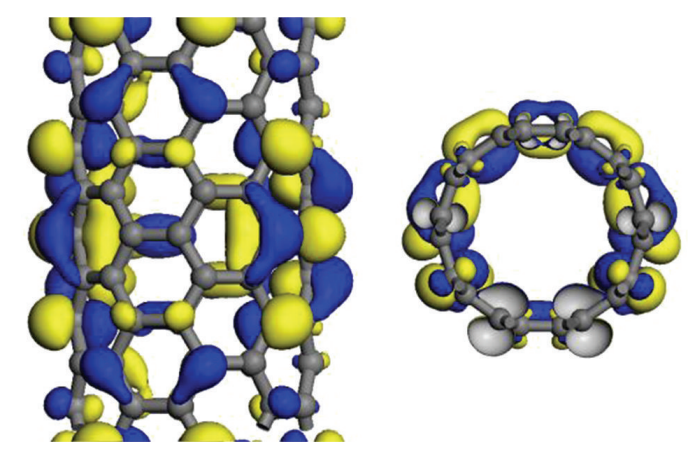

(b)
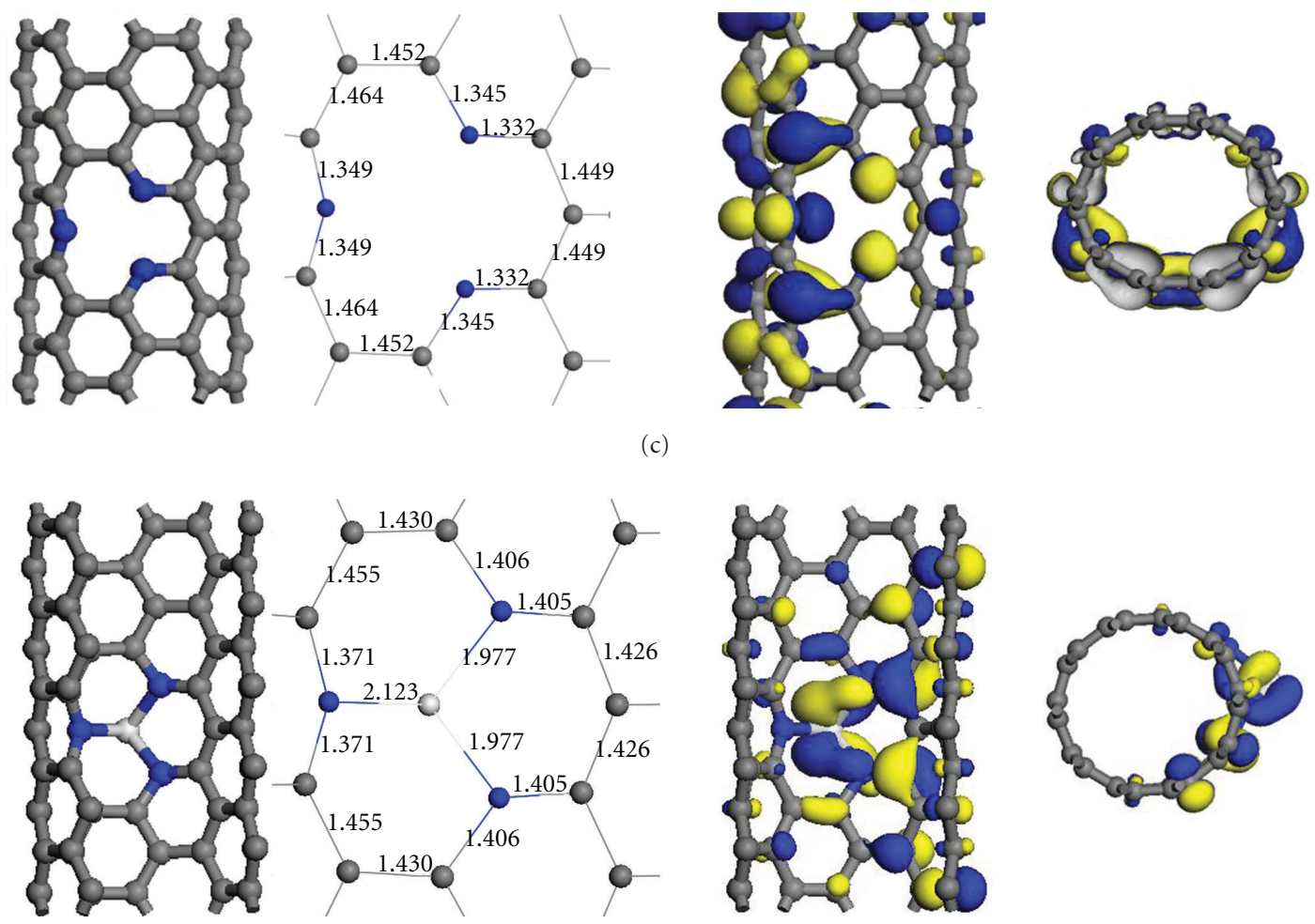

(d)

Figure 2: Geometrically optimized structures, bond lengths $(\AA)$, and highest occupied molecular orbital (HOMO) of (a) pure zigzag (5,

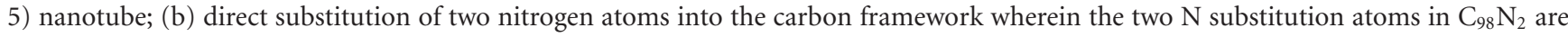
in the opposite positions; (c) N substitution into the carbon framework with the formation of pyridine-like vacancy: pyridine-like doping $\mathrm{C}_{92} \mathrm{~N}_{6}$ wherein two vacancies are formed in opposite positions and (d) adsorption configuration of the transition metal on a nanotube with pyridine-like defect. Grey ball denotes $\mathrm{C}$ atom, blue ball denotes $\mathrm{N}$ atom, and white denotes TM (Sc). A fragment of the supercell was taken out to elucidate the bong lengths at the vicinity of the impurities. 
TAble 1: Calculated deformation $(\delta)$ of the $(10,0)$ and $(5,5)$ nitrogenated SWCNTs.

\begin{tabular}{|c|c|c|}
\hline & System & $\delta$ \\
\hline \multirow{4}{*}{$(10,0)$} & Pure $\mathrm{C}_{120}$ & 1.0 \\
\hline & Substitution, $\mathrm{C}_{118} \mathrm{~N}_{2}$ & 1.1 \\
\hline & Pyridine-like, $\mathrm{C}_{112} \mathrm{~N}_{6}$ & 1.1 \\
\hline & $\mathrm{Sc} / 3 \mathrm{NV}-\mathrm{CN}_{x} \mathrm{NT}, \mathrm{ScC}_{116} \mathrm{~N}_{3}$ & 1.1 \\
\hline \multirow{4}{*}{$(5,5)$} & Pure $\mathrm{C}_{100}$ & 1.0 \\
\hline & Substitution, $\mathrm{C}_{98} \mathrm{~N}_{2}$ & 1.1 \\
\hline & Pyridine-like, $\mathrm{C}_{92} \mathrm{~N}_{6}$ & 1.3 \\
\hline & $\mathrm{Sc} / 3 \mathrm{NV}-\mathrm{CN}_{x} \mathrm{NT}, \mathrm{ScC}_{96} \mathrm{~N}_{3}$ & 1.1 \\
\hline
\end{tabular}

TABLE 2: Calculated average TM-N bond lengths $\left(D_{\mathrm{TM}-\mathrm{N}}\right)$, binding energies $\left(E_{b}\right)$ of various TMs adsorbed on $(10,0)$ and $(5,5)$ CNT with pyridine-like defect, the charge transferred (C) from TM to the $(10,0)$ and $(5,5) \mathrm{CNT}$ with pyridine-like defect, and the net magnetic moment $\left(\mu_{\text {total }}\right)$ of the $(10,0)$ and $(5,5)$ CNT with pyridine-like defect functionalized with transition metals.

\begin{tabular}{cccccc}
\hline System & $\begin{array}{c}D_{\mathrm{TM}-\mathrm{N}} \\
(\AA)\end{array}$ & $\begin{array}{c}E_{b} \\
(\mathrm{eV})\end{array}$ & $\begin{array}{c}\mathrm{C} \\
(\mathrm{e})\end{array}$ & $\begin{array}{c}\mu_{\text {total }} \\
\left(\mu_{\mathrm{B}}\right)\end{array}$ \\
\hline $\mathrm{Sc}$ & 2.02 & 7.16 & 0.70 & 0.00 \\
$\mathrm{Ti}$ & 1.95 & 6.97 & 0.57 & 0.98 \\
$\mathrm{~V}$ & 1.93 & 6.18 & 0.43 & 2.28 \\
$\mathrm{Cr}$ & 1.87 & 4.31 & 0.52 & 1.74 \\
$\mathrm{Hn}, 0)$ & 1.85 & 4.47 & 0.27 & 0.00 \\
$\mathrm{Mn}$ & 1.84 & 5.64 & 0.29 & 0.00 \\
$\mathrm{Fe}$ & 1.87 & 5.60 & 0.21 & 1.37 \\
$\mathrm{Co}$ & 1.86 & 4.85 & 0.19 & 1.09 \\
$\mathrm{Ni}$ & 1.93 & 3.41 & 0.31 & 0.00 \\
$\mathrm{Cu}$ & 1.94 & 1.86 & 0.42 & 0.00 \\
$\mathrm{Zn}$ & 2.19 & 2.36 & 0.36 & 0.00 \\
$\mathrm{Pd}$ & 2.33 & 1.86 & 0.36 & 0.00 \\
$\mathrm{Ag}$ & 2.09 & 2.66 & 0.25 & 0.00 \\
$\mathrm{Pt}$ & 2.38 & 1.08 & 0.23 & 0.00 \\
\hline $\mathrm{Au}$ & 2.02 & 7.01 & 0.70 & 0.00 \\
$\mathrm{Sc}$ & 1.98 & 6.59 & 0.55 & 1.39 \\
$\mathrm{Ti}$ & 1.96 & 5.92 & 0.42 & 2.54 \\
$\mathrm{~V}$ & 1.88 & 4.13 & 0.55 & 2.05 \\
$\mathrm{Cr}$ & 1.85 & 4.32 & 0.27 & 0.00 \\
$\mathrm{Mn}$ & 1.84 & 5.59 & 0.28 & 0.00 \\
$\mathrm{Fe}$ & 1.87 & 5.53 & 0.20 & 1.41 \\
$\mathrm{Co}$ & 1.86 & 4.67 & 0.19 & 1.11 \\
$\mathrm{Ni}$ & $\mathrm{Cu}$ & 3.33 & 0.32 & 0.00 \\
$\mathrm{Zn}$ & 1.93 & 1.71 & 0.45 & 0.00 \\
$\mathrm{Pd}$ & 2.19 & 2.25 & 0.36 & 0.00 \\
$\mathrm{Ag}$ & 2.33 & 1.76 & 0.36 & 0.00 \\
$\mathrm{Pt}$ & 2.12 & 2.56 & 0.25 & 0.00 \\
$\mathrm{Au}$ & 1.14 & 0.25 & 0.00 \\
\hline
\end{tabular}

a $(10,0)$ nanotubes $(\delta \approx 1.1)$ due to the smaller diameter of $(5,5)$ nanotube.
The bond lengths of the relaxed nanotubes in the vicinity of the nitrogen impurities are also displayed in Figures 1 and 2. The $\mathrm{C}-\mathrm{N}$ bond lengths of direct nitrogen substitution are determined to be $\sim 1.39-1.42 \AA$ for the doped nanotubes both in Figures 1(b) and 2(b). Due to the missing central $\mathrm{C}$ atom, the $\mathrm{C}-\mathrm{N}$ bond lengths of pyridinelike doping are determined to be $\sim 1.33-1.35 \AA$, depending on the orientation, as compared to $\sim 1.42-1.43 \AA$ for the C$\mathrm{C}$ bonds (see Figures 1(c) and 2(c)). The relaxed structures of nitrogenated SWNTs correlate well with experimental observations of nitrogen-doped CNTs [14, 48]. We consider the TM is directly bound to the site of $3 \mathrm{NV}$ and the TM is attached to the sites near $3 \mathrm{NV}$ as initial guesses. After full structural optimization, we find that the TM adsorptions on the defect sites (Figures 1(d) and 2(d)) are the most stable because of their higher reactivity than other sites $[16,20$, 21, 38-43]. Accordingly, in Table 2, we list the structural parameters most stable configurations of TMs adsorbed on the two $3 \mathrm{NV}-\mathrm{CN}_{x} \mathrm{NT}$ (labeled as TM/3 NV-CN ${ }_{x} \mathrm{NT}$ ). We find that these most stable configurations of TM/3 NV$\mathrm{CN}_{x} \mathrm{NT}$ nanotubes are characterized as forming multiple $\mathrm{TM}-\mathrm{N}$ bonds at the vacancy sites due to the $\mathrm{N}$ participation. All the TMs are projecting from the sidewall of the two $3 \mathrm{NV}$ $\mathrm{CN}_{x}$ NTs in various ways. Moreover, as shown in Table 2, the average TM-N distances $\left(D_{\mathrm{TM}-\mathrm{N}}\right)$ of TM/CN $\mathrm{CN}_{x} \mathrm{NT}$ nanotubes with $3 \mathrm{NV}$ defects range from $1.84(\mathrm{Fe})$ to $2.38(\mathrm{Au}) \AA$ for $(10$, $0)$ and from $1.84(\mathrm{Fe})$ to $2.46(\mathrm{Au}) \AA$ for $(5,0)$. Thus, it can be surmised that $\mathrm{N}$ and TM impurities in CNTs produce their own local strains and result in the respective deformation.

The effects of dissimilar nitrogenation on armchair and zigzag nanotubes are also reflected by the differences in the HOMO distribution. For instance, the HOMO of a nitrogen substituted $(10,0)$ nanotube is polarized at two opposite nitrogen dopants, while this is not the case for a nitrogensubstituted $(5,5)$ nanotube (see Figures $1(\mathrm{~b})$ and 2(b)). Pyridine-like doping causes the HOMO of doped $(5,5)$ nanotube to be more concentrated at one side of the ellipsoidal ring (see Figures 1(c) and 2(c)). The HOMO of the nanotube functionalized with a TM is polarized at the TM dopants for both $(10,0)$ and $(5,5)$ nanotubes (see Figures 1(d) and 2(d)).

3.2. Formation Energies. We choose the $(10,0)$ tube as a typical semiconducting tube for investigation and suggest that two nitrogen-doped atoms might be very near to or far from each other, but which configuration is favorably stable completely depends on its formation energy. Stability can be assessed by calculating the formation energies $\left(E_{f}\right)$ defined as:

$$
E_{f}=E_{\mathrm{tot}}-n_{\mathrm{C}} \mu_{\mathrm{C}}-n_{\mathrm{N}} \mu_{\mathrm{N}},
$$

where $E_{\text {tot }}$ is the total energy of the $(10,0)$ and $(5,5)$ $\mathrm{CN}_{x} \mathrm{NT}, n_{\mathrm{C}}$ and $n_{\mathrm{N}}$ are the number of $\mathrm{C}$ and $\mathrm{N}$ atoms, respectively. $\mu_{\mathrm{C}}$ is the chemical potential of $\mathrm{C}$ obtained from the corresponding pure CNT, and $\mu_{\mathrm{N}}$ is the chemical potential of $\mathrm{N}$ obtained from nitrogen in gas phase. There are six configurations in which adjacent nitrogen substituted (NS) atoms are near and lie in the same hexagon, as shown 


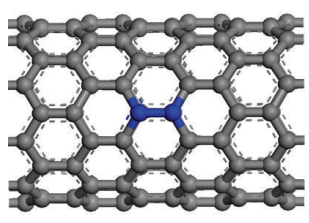

(a) NS1

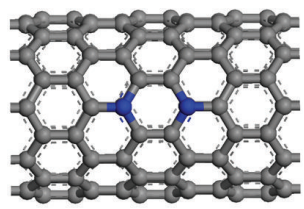

(e) NS5

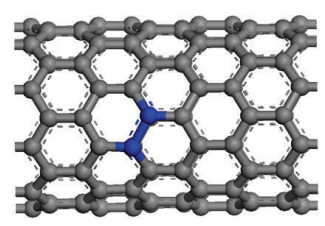

(b) NS2

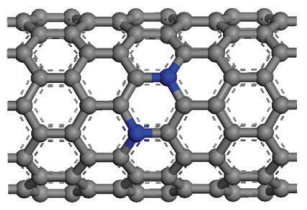

(f) NS6

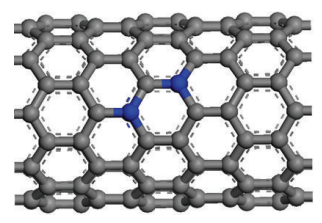

(c) NS3

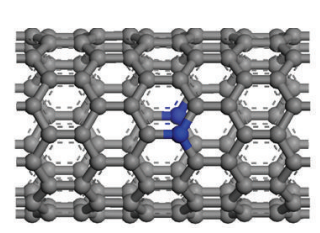

(g) NS7

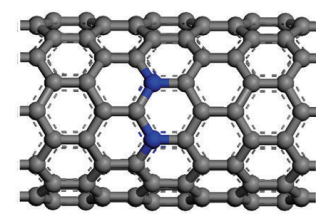

(d) NS4

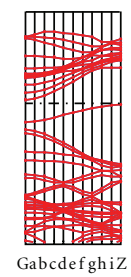

(h)

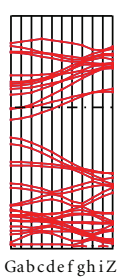

(i)

FIGURE 3: Geometrically optimized structures of the configurations for $(10,0)$ tubes containing two substitutional nitrogen atoms per five tube units denoted by (a) NS1- (g) NS7, respectively, and the bandstructures of (h) NS5 and (i) NS7 configurations. Substitutional nitrogen atoms are denoted by blue balls, and grey ball is $\mathrm{C}$ atom.

in Figure 3, which are denoted by NS1 to NS6. For the other case, the typical configuration that the two nitrogen atoms are apart is chosen, denoted by NS7 as shown in Figure 3(g) The formation energies of the nitrogenated SWNTs are given in Table 3. It is clear from the table that NS1 and NS2 atoms shown in Figures 3(a) and 3(b) are energetically unfavorable and that the most stable is NS5, shown in Figure 3(e), because its configuration is symmetric along the tube axis. The stable configurations for $\mathrm{CN}_{x} \mathrm{NTs}$ are sensitive to symmetry. NS6 and NS7 have the same formation energies. Interestingly, if we compare the band structures of two nitrogen-doped atoms near to or far from each other (NS5 and NS7), we see from Figures 3(h) and 3(i) that NS5 is still a semiconductor while NS7 has been transformed to metallic. This motivates us to choose NS7 as a model for investigating the effects of nitrogen substitution for $(10,0)$ nanotubes. Particularly, the model is so chosen to represent the effects of nitrogen doping on CNTs atomic deformation, molecular orbital, electronic structures, and properties.

The energy cost to $s p^{2}$-substitute a $\mathrm{C}$ atom with an $\mathrm{N}$ atom in $(10,0)$ and $(5,5)$ nanotubes are 0.93 and $0.97 \mathrm{eV}$, respectively. On the other hand, it costs 3.16 and $2.96 \mathrm{eV}$ to form pyridine-like doping in $(10,0)$ and $(5,5)$ nanotubes, respectively. The synthesis of $\mathrm{N}$-doped carbon nanotubes is usually carried out at $700-900^{\circ} \mathrm{C}$ using nitrogen-rich precursors for CVD processes [14, 49, 50]. Spectroscopic studies and peak analysis revealed that $\mathrm{C}-\mathrm{N}$ bonding of $\mathrm{N}$-doped carbon nanotubes involved $s p^{2}, s p^{3}$-typed, and intercalated $\mathrm{N}_{2}$ as well, which might be attributed to $s p^{2}$ substitution of $\mathrm{C}$ atom with an $\mathrm{N}$ atom, pyridine-like doping, and molecular $\mathrm{N}_{2}$, respectively. The relatively high synthesis temperature and use of catalysts might provide sufficient energies to form pyridine-like defects in $\mathrm{N}$-doped carbon nanotubes, though the formation energies of pyridine-like defects are higher than $s p^{2}$-substitution.
TABLE 3: The formation energies of N-substituted (NS), pyridinelike and porphyrine-like doped SWCNTs.

\begin{tabular}{|c|c|c|}
\hline & System & $E_{f}(\mathrm{eV})$ \\
\hline \multirow{13}{*}{$(10,0)$} & NS1 & 3.12 \\
\hline & NS2 & 2.75 \\
\hline & NS3 & 2.30 \\
\hline & NS4 & 2.30 \\
\hline & NS5 & 1.84 \\
\hline & NS6 & 2.12 \\
\hline & NS7 & 2.15 \\
\hline & Substitution, $\mathrm{C}_{119} \mathrm{~N}_{1}$ & 0.93 \\
\hline & Substitution, $\mathrm{C}_{118} \mathrm{~N}_{2}$ & 1.93 \\
\hline & Pyridine-like, $\mathrm{C}_{116} \mathrm{~N}_{3}$ & 3.16 \\
\hline & Pyridine-like, $\mathrm{C}_{112} \mathrm{~N}_{6}$ & 6.36 \\
\hline & Porphyrine-like, $\mathrm{C}_{114} \mathrm{~N}_{4}$ & 3.20 \\
\hline & Porphyrine-like, $\mathrm{C}_{108} \mathrm{~N}_{8}$ & 6.11 \\
\hline \multirow{4}{*}{$(5,5)$} & Substitution, $\mathrm{C}_{99} \mathrm{~N}_{1}$ & 0.97 \\
\hline & Substitution, $\mathrm{C}_{98} \mathrm{~N}_{2}$ & 1.99 \\
\hline & Pyridine-like, $\mathrm{C}_{96} \mathrm{~N}_{3}$ & 2.96 \\
\hline & Pyridine-like, $\mathrm{C}_{92} \mathrm{~N}_{6}$ & 5.89 \\
\hline
\end{tabular}

3.3. Binding Energies. Two kinds of functionalized $3 \mathrm{NV}$ $\mathrm{CN}_{x} \mathrm{NT}$ with TMs were considered, as shown in Figures 1(d) and $2(\mathrm{~d})$, The binding energy $\left(E_{b}\right)$ in Table 2 of an individual $\mathrm{TM}$ on the $3 \mathrm{NV}-\mathrm{CN}_{x} \mathrm{NT}$ nanotube was defined as

$$
\begin{aligned}
E_{b}= & E_{\mathrm{tot}}\left(3 \mathrm{NV}-\mathrm{CN}_{x} \mathrm{NT}\right)+E_{\mathrm{tot}}(\mathrm{TM}) \\
& -E_{\mathrm{tot}}\left(\mathrm{TM} / 3 \mathrm{NV}-\mathrm{CN}_{x} \mathrm{NT}\right),
\end{aligned}
$$


where $E_{\text {tot }}$ denotes the total energy of the optimized system in the bracket. $E_{b}>0$ corresponds to a stable optimized configuration and indicates bonding. On the other hand, due to the $\mathrm{N}$ participation and the vacancy defect, the binding energies of all TMs on the two $3 \mathrm{NV}-\mathrm{CN}_{x} \mathrm{NTs}$ are generally larger than those on the pure CNTs $[51,52]$ as shown in Figure 4(a). Formation of pyridine-like nitrogen defects is very crucial for enhancing the metal binding to the defects. Moreover, the variation of the binding energy as the number of $d$ electrons for these TMs is also given in Figure 4(a); we find that Sc $\left(3 d^{1} 4 s^{2}\right)$ forms the stronger bonds with $E_{b}$ around $8 \mathrm{eV}$ with respect to the others, which well agrees with previous study [40]. On the contrary, the binding energies of $\mathrm{Zn}\left(3 d^{10} 4 s^{2}\right)$ on the two $3 \mathrm{NV}-\mathrm{CN}_{x} \mathrm{NT}$ are the smallest around $2 \mathrm{eV}$.

The strong interactions between these TMs and the two $3 \mathrm{NV}-\mathrm{CN}_{x} \mathrm{NTs}$ can be explained through the local densities of states (LDOS) and partial densities of states (PDOS), that is, $\mathrm{Sc}$ adsorption on the $3 \mathrm{NV}-\mathrm{CN}_{x} \mathrm{NT}$ as shown in Figures $4(\mathrm{~b})-4(\mathrm{e})$ for the $(10,0)$ and Figures $4(\mathrm{f})-4(\mathrm{i})$ for the $(5$, $5)$. It is found that, in both tubes, the d electrons of Sc and the $p$ electrons of $\mathrm{C}$ and $\mathrm{N}$ atoms mainly contribute to the electronic states near Fermi level. In other words, strong interaction exists between the $d$ orbitals of Sc and the $p$ orbitals of $\mathrm{N}$ atoms due to their hybridization with each other.

3.4. Electronic Properties. Figure 5(a) shows the band structure of a pure $(10,0)$ nanotube. The top most valence band and bottom conduction band correspond to the big $\pi$ bonding and $\pi^{*}$-antibonding states along the ring of the tube, respectively. Upon nitrogenation, the degeneracies of the energy bands of $(10,0)$ nanotubes are removed. The presence of nitrogen impurities causes the band to split. Band structures of Figures 5(a) $-5(\mathrm{~d})$ are consistent to that of [53]. As in the case of semiconducting $(10,0)$ nanotubes, substitutional doping does not disturb the $s p^{2}$ hybridization of the $\pi$-electrons and the $\mathrm{N}$ impurity states contributes mainly to the conduction band minimum.

The electronic band structures of pure and doped $(5,5)$ nanotubes are displayed in Figures 6(a)-6(d). The $\pi-\pi^{*}$ band crossing of the pure $(5,5)$ metallic tube is disturbed by the presence of $\mathrm{N}$ impurities. Small band gaps open up between the conduction and valence bands, which are attributed to the breaking of the armchair nanotube mirror symmetry due to the tube-impurity interaction. The opening of small gaps has also been reported for covalently functionalized and $\mathrm{Cu}-$ adsorbed metallic nanotubes $[53,54]$.

In Figures 7(a)-7(d), we present the electronic density of states (DOS) of pristine and NS $(10,0)$ nanotubes. At low concentration of dopants around $0.83 \%$, direct substitution of nitrogen narrows the band gap. At higher level of doping, the band gap continues to narrow and eventually filled with impurity states at higher concentration of dopants. For instance, NS $(10,0)$ nanotubes of $1.67 \%$ concentration become metallic due to the finite states at the Fermi level (see Figure $7(\mathrm{c})$ ).

To investigate the effects of nitrogen impurities in the pyridine-like vacancy, we have also computed the DOS of a $(10,0)$ tube with pyridine-like vacancy but without nitrogen dopants (see the expanded view in Figure $7(d)$, red curve). The relaxed geometry of such a $(10,0)$ tube with monovacancy without $\mathrm{N}$-impurities shows that it is a semiconductor, while the $(10,0)$ tube with pyridine-like nitrogen doping shows that it is a metal. Therefore, the observed finite states at the Fermi level is due to the nitrogen dopants and not to the monovacancy.

Since NS5 is the most stable configuration and is a semiconductor, the observed finite states for NS7 may not indicate that the direct substitution of nitrogen will make nanotubes metallic. However, as we increase the doping concentration for NS5 from $1.67 \%$ to $3.33 \%$ (see Figure 7(e)) which is four substitutional nitrogen atoms per five tube units, the resulting DOS is indeed a metal confirming our observation.

The electronic density of states of pure and NS armchair $(5,5)$ nanotubes are displayed in Figures $7(\mathrm{f})-7(\mathrm{i})$. The effects of $\mathrm{N}$ doping for $(5,5)$ can be seen from Figures $7(\mathrm{f})$ 7 (i) to significantly enhance the state density near the Fermi level. The DOS of pure $(5,5)$ tubes exhibits a finite DOS at the Fermi level, which renders it metallic, and, at higher level of doping, the DOS shows a sharp peak at the Fermi level. For the case of $(5,5)$ tube with pyridine-like doping (Figure 7(i)), again a peak at the Fermi level is also observed. Likewise, we have also computed the DOS of $(5,5)$ tubes with pyridinevacancy without $\mathrm{N}$-impurities, and its DOS also shows a sharp peak at the Fermi level (Figure 7(i), red region). The DOS of pyridine-like NS $(5,5)$ tube is quite similar to $(5,5)$ tubes with monovacancy without $\mathrm{N}$-impurities. Therefore, the observed DOS peak at the Fermi level of the pyridinelike nitrogenated $(5,5)$ tube is due to the vacancy and not the nitrogen dopants.

Chemical functionalization of nanotubes with the TMs is a key to creation of new energy levels in the band gap with associated electronic states. In Figures $5(\mathrm{e})-5(\mathrm{p})$ and Figures $6(\mathrm{e})-6(\mathrm{p})$, band structures of different $\mathrm{TM} / \mathrm{CN}_{x} \mathrm{NT}$ nanotubes were presented. It can be seen that $(10,0)$ and $(5,5) \mathrm{CN}_{x} \mathrm{NTs}$ with $3 \mathrm{NV}$ exhibit metallic nature (Figures 5(d) and 6(d)), which are in good agreement with [21]. Upon adsorption of these TMs on the two $\mathrm{CN}_{x} \mathrm{NTs}$, certain impurity states are introduced into their band structures, rendering the electronic properties to change to different degrees that are strongly dependent on the adsorbed TMs. For example, when $\mathrm{V}, \mathrm{Cu}, \mathrm{Zn}, \mathrm{Ag}, \mathrm{Pt}$, and $\mathrm{Au}$ are adsorbed on the two $\mathrm{CN}_{x} \mathrm{NTs}$, several semiconductors nanocomposites are obtained as their band gaps are increased to different degrees due to the lift of the conduction bands of the two $\mathrm{CN}_{x}$ NTs.

Interestingly, for Ti adsorptions the influences on electronic properties of the two $\mathrm{CN}_{x} \mathrm{NTs}$ are completely different: for the Ti adsorption, the $(10,0) \mathrm{CN}_{x} \mathrm{NT}$ with $3 \mathrm{NV}$ defect is changed into a semiconductor while the $(5,5) \mathrm{CN}_{x} \mathrm{NT}$ with $3 \mathrm{NV}$ defect has a half-metallic nature. This means that $\mathrm{CN}_{x}$ NT-based devices with various electronic properties can be achieved.

The changes in band structures of the $\mathrm{CN}_{x} \mathrm{NTs}$ upon adsorption of these TMs are also evident by the charge transfer between the TM and the $\mathrm{CN}_{x} \mathrm{NT}$. In Table 2, we 


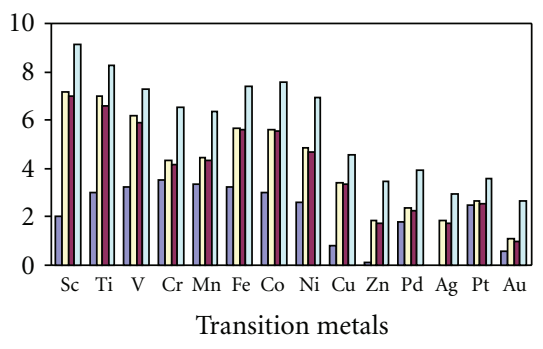

- $\operatorname{Pure}(10,0)$

- $\mathrm{TM} /(10,0) 3 \mathrm{NV}$

- $\mathrm{TM} /(5,5) 3 \mathrm{NV}$

- $\mathrm{TM} /(10,0) 4 \mathrm{ND}$

(a)

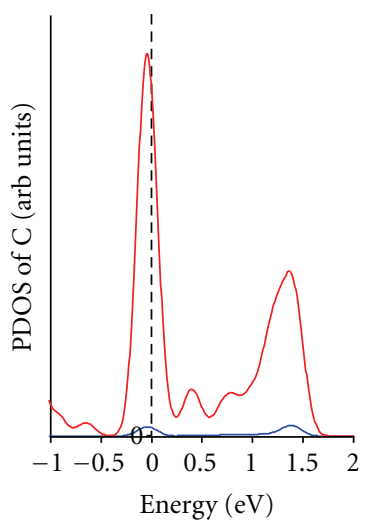

$-\mathrm{s}$

(d)

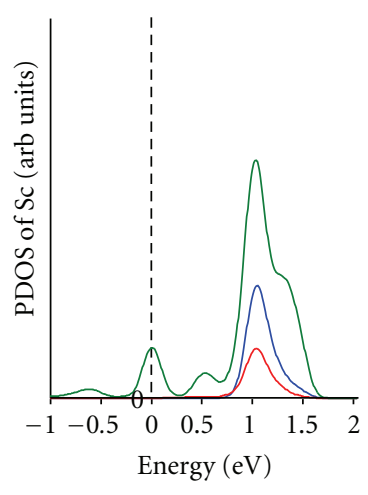

$\mathrm{s}$
$-\mathrm{p}$
$-\mathrm{d}$

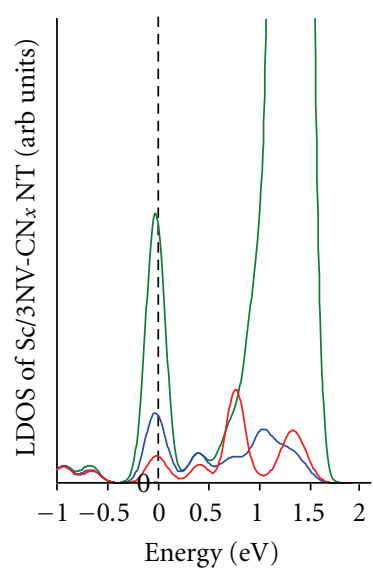

$-\mathrm{Sc}$

$-\mathrm{C}$

(b)

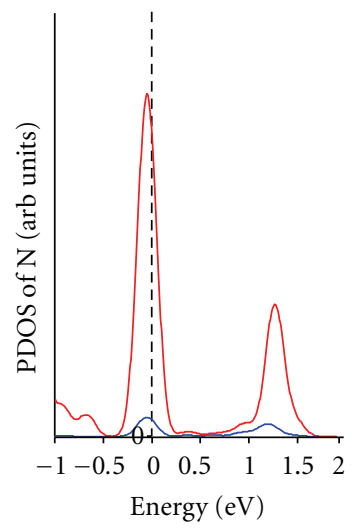

$-\mathrm{s}$

(e)

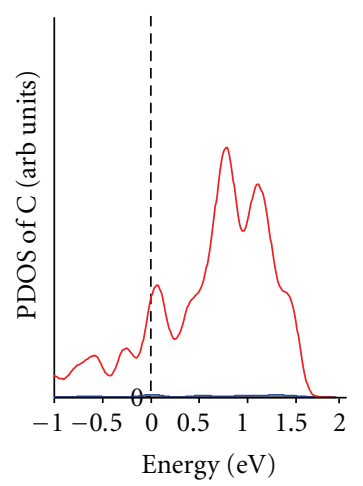

$-\mathrm{s}$
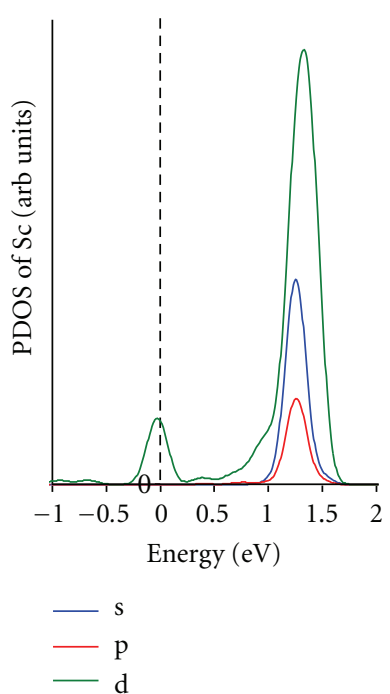

(c)

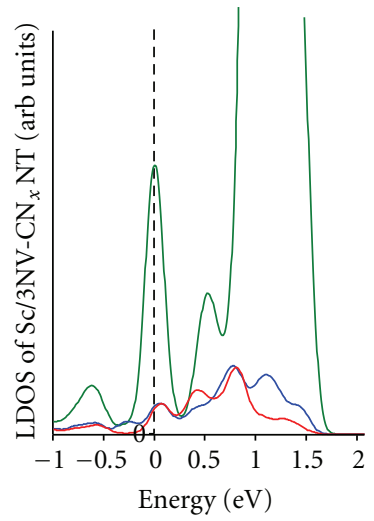

$-\mathrm{Sc}$

$-\mathrm{C}$

$-\mathrm{N}$

(f)

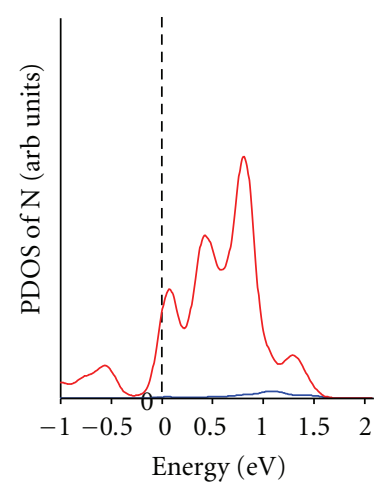

$-\mathrm{s}$

(g)

(h)

(i)

FIgure 4: (a) Plot of the calculated binding energies $\left(E_{b}\right)$ in eV of the 14 different TMs on the pure $(10,0)$ CNT without pyridine-like defects, $(10,0)$ and $(5,5)$ CNT with pyridine-like defects, and $(10,0)$ CNT with porphyrine-like defects; there is no available data on Ag on the pure $(10,0)$ CNT without pyridine-like defects for comparison. (b) The local densities of states (LDOS) of a Sc adsorbed on the (10, 0) CNT with pyridine-like defects $\mathrm{C}_{116} \mathrm{~N}_{3}$ and the partial densities of states (PDOS) of (c) Sc, (d) C, and (e) N in the adsorption system for the (10, 0) CNT. (f) The LDOS of a Sc adsorbed on the $(5,5)$ CNT with pyridine-like defects $\mathrm{C}_{96} \mathrm{~N}_{3}$ and the PDOS of (g) Sc, (h) C, and (i) N in the adsorption system for the $(5,5) \mathrm{CNT}$. A smearing of $0.05 \mathrm{eV}$ was applied for all graphs. 


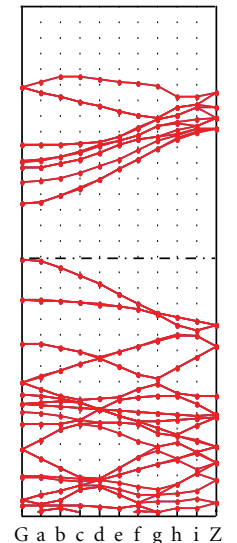

(a) Pure $(10,0)$

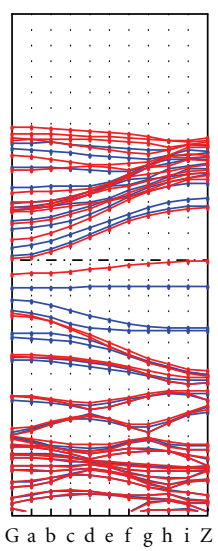

(g) $\mathrm{V} / 3 \mathrm{NV}$

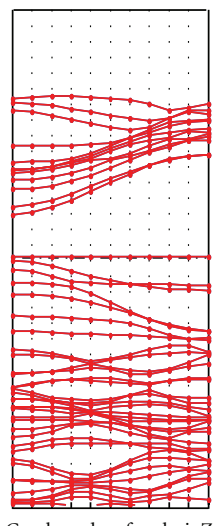

Gabcdef gh i Z

(m) $\mathrm{Cu} / 3 \mathrm{NV}$

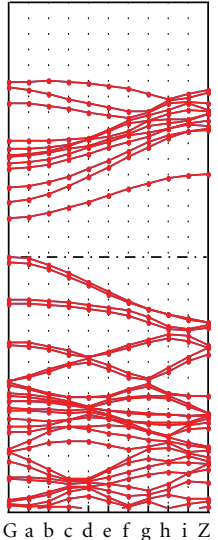

(b) $\mathrm{C}_{119} \mathrm{~N}_{1}$

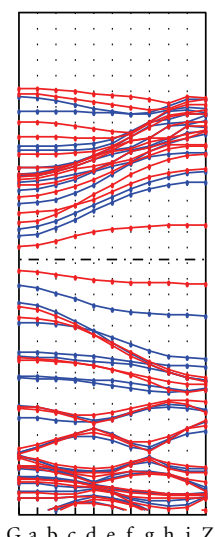

(h) $\mathrm{Cr} / 3 \mathrm{NV}$

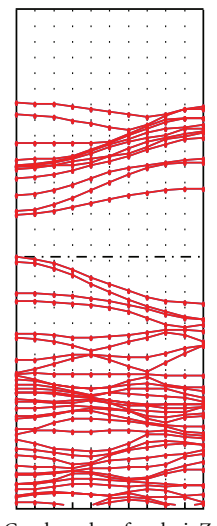

(n) $\mathrm{Zn} / 3 \mathrm{NV}$

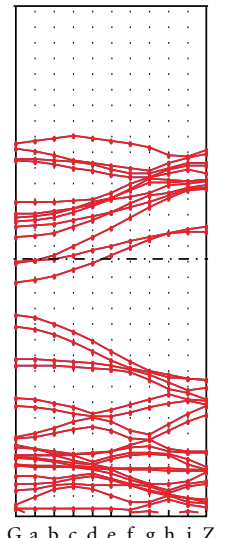

(c) $\mathrm{C}_{118} \mathrm{~N}_{2}$

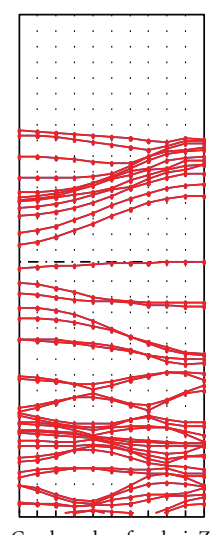

Gabcdefghi $Z$

(i) $\mathrm{Mn} / 3 \mathrm{NV}$

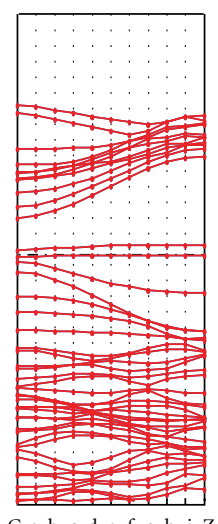

(o) $\mathrm{Pd} / 3 \mathrm{NV}$

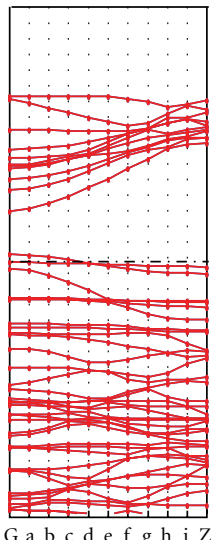

(d) $3 \mathrm{NV}-\mathrm{CN}_{x} \mathrm{NT}$

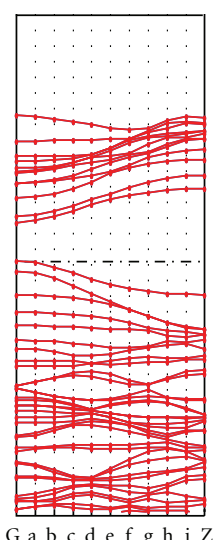

(j) $\mathrm{Fe} / 3 \mathrm{NV}$

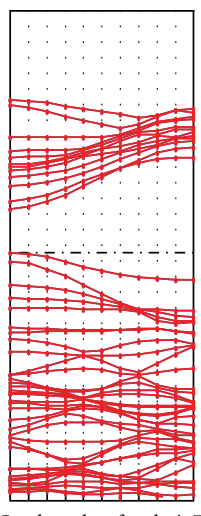

(p) $\mathrm{Ag} / 3 \mathrm{NV}$

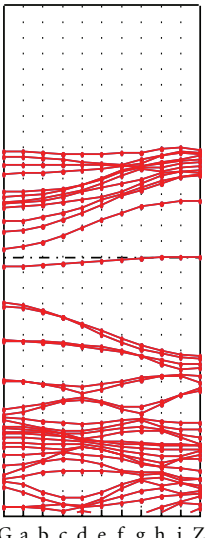

(e) $\mathrm{Sc} / 3 \mathrm{NV}$

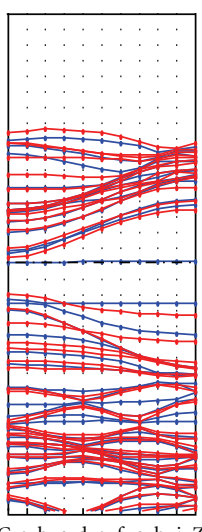

(k) $\mathrm{Co} / 3 \mathrm{NV}$

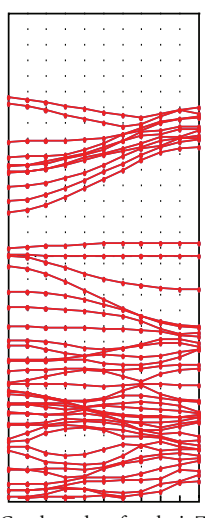

(q) $\mathrm{Pt} / 3 \mathrm{NV}$

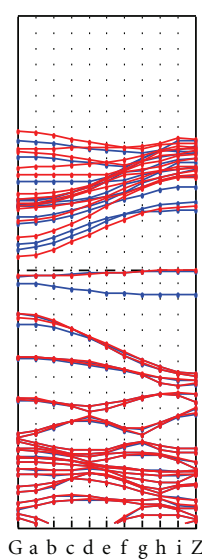

(f) $\mathrm{Ti} / 3 \mathrm{NV}$

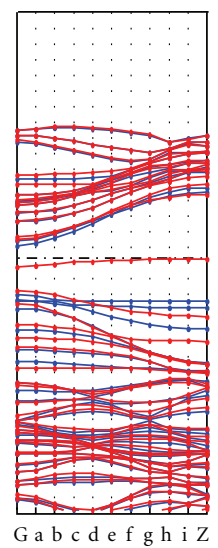

(l) $\mathrm{Ni} / 3 \mathrm{NV}$

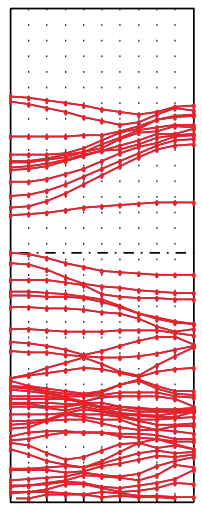

Gabcdefghi Z

(r) $\mathrm{Au} / 3 \mathrm{NV}$

FIgURE 5: Band structures of TMs adsorbed on $(10,0)$ zigzag $\mathrm{CN}_{x} \mathrm{NT}$ with $3 \mathrm{NV}$ defect. The Fermi level is set as zero and plotted with a line. The blue and red plots denote alpha and beta band structures, respectively. Only one part indicates that this system is nonmagnetic. Energies at the vertical axis are at arbitrary units.

list the calculated charge transfer using Hirshfeld population analysis [55], the charges transferred from TMs to the (10, 0 ) $\mathrm{CN}_{x} \mathrm{NT}$ with $3 \mathrm{NV}$ defect range from $0.70 \mathrm{e}$ (for $\mathrm{Sc}$ ) to 0.16 e (for $\mathrm{Ni}$ ), while the range of charge transfer is from 0.70 e (for Sc) to 0.19 e (for Ni) in the case of $(5,5) 3 \mathrm{NV}-\mathrm{CN}_{x} \mathrm{NT}$. The charge transfer leads to the partially cationic TMs, and, thus, facilitating the adsorption of foreign species such as hydrogen gas, it follows that $3 \mathrm{NV}-\mathrm{CN}_{x} \mathrm{NT}$ doped with TMs is a potential material for hydrogen storage.

Formation energies of $(10,0)$ SWCNTs with porphyrinelike vacancy are given in Table 3. It is clear from the table that pyridine-like and porphyrine-like vacancies are both 


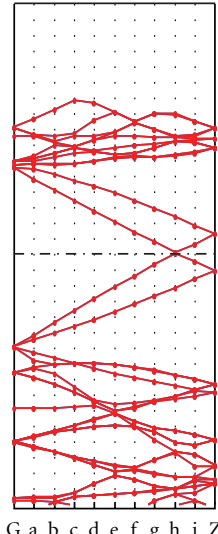

(a) Pure $(5,5)$

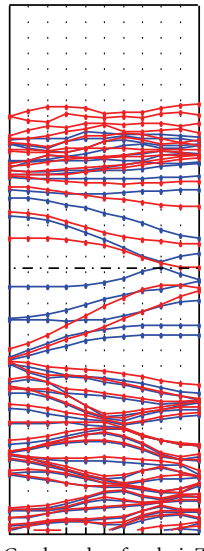

(g) $\mathrm{V} / 3 \mathrm{NV}$

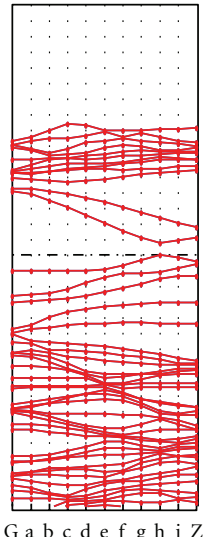

(m) $\mathrm{Cu} / 3 \mathrm{NV}$

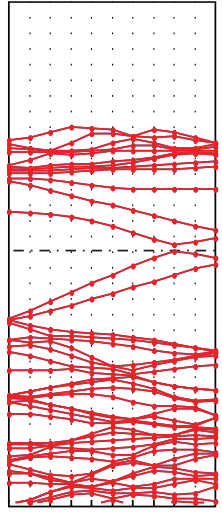

$\mathrm{Gabcdef} g \mathrm{hi}$

(b) $\mathrm{C}_{99} \mathrm{~N}_{1}$

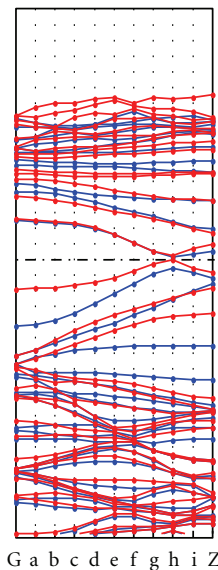

(h) $\mathrm{Cr} / 3 \mathrm{NV}$

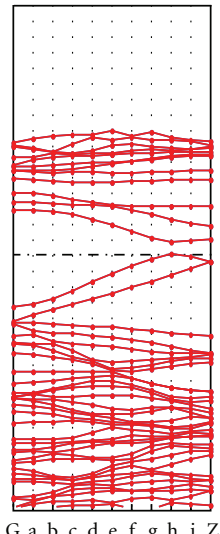

(n) $\mathrm{Zn} / 3 \mathrm{NV}$

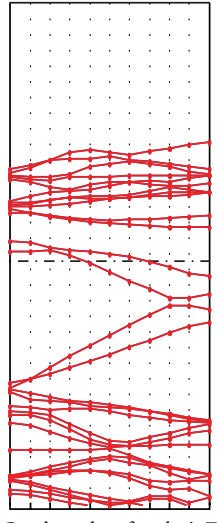

(c) $\mathrm{C}_{98} \mathrm{~N}_{2}$

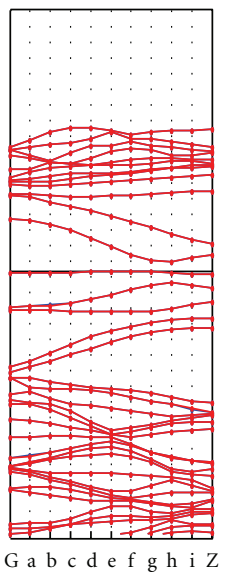

(i) $\mathrm{Mn} / 3 \mathrm{NV}$

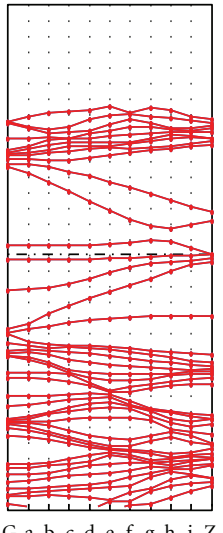

(o) $\mathrm{Pd} / 3 \mathrm{NV}$

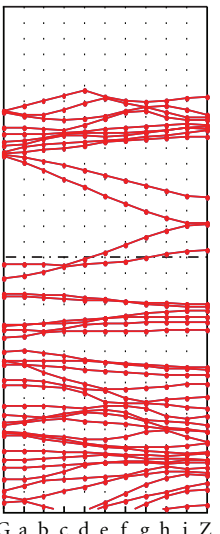

(d) $3 \mathrm{NV}-\mathrm{CN}_{x} \mathrm{NT}$

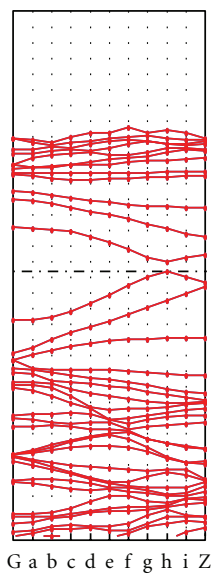

(j) $\mathrm{Fe} / 3 \mathrm{NV}$

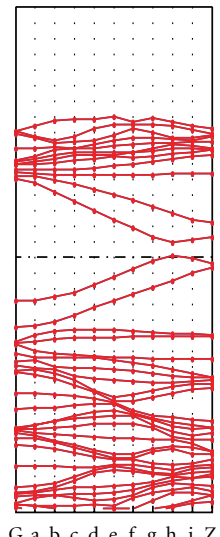

(p) $\mathrm{Ag} / 3 \mathrm{NV}$

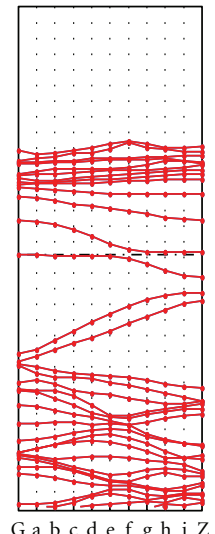

(e) $\mathrm{Sc} / 3 \mathrm{NV}$

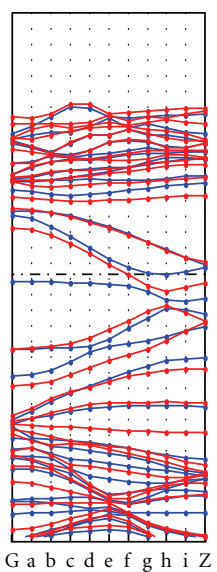

(k) $\mathrm{Co} / 3 \mathrm{NV}$

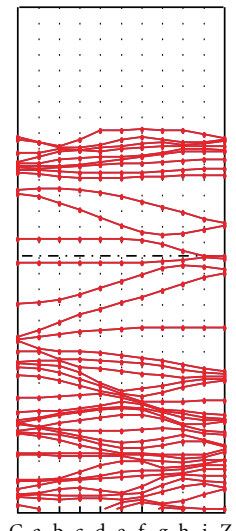

(q) $\mathrm{Pt} / 3 \mathrm{NV}$

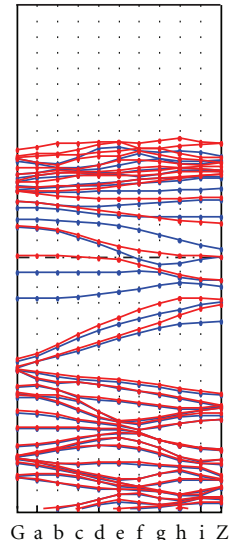

(f) $\mathrm{Ti} / 3 \mathrm{NV}$

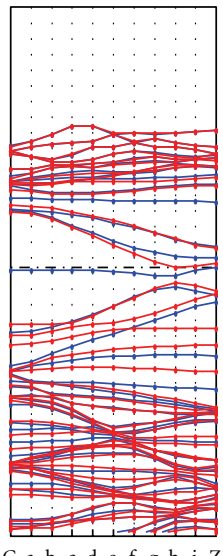

(l) $\mathrm{Ni} / 3 \mathrm{NV}$

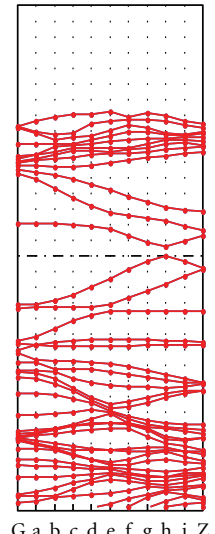

(r) $\mathrm{Au} / 3 \mathrm{NV}$

FIGURE 6: Band structures of TMs adsorbed on $(5,5)$ armchair $\mathrm{CN}_{x} \mathrm{NT}$ with $3 \mathrm{NV}$ defect. The Fermi level is set as zero and plotted with a line. The blue and red plots denote alpha and beta band structures, respectively. Only one part indicates that this system is nonmagnetic. Energies at the vertical axis are at arbitrary units.

energetically favorable and are equally likely to occur at high synthesis temperature; therefore we also model out a SWCNT with porphyrine-like vacancies (Figure 8(a)) and a $4 \mathrm{ND}-\mathrm{CN}_{x} \mathrm{NT}$ that is chemically functionalized with 14 TMs (Figures $8(\mathrm{~b})-8(\mathrm{o})$ ) for completeness and comparison with the pyridine-like case. The binding energy of the 4ND$\mathrm{CN}_{x} \mathrm{NT}$ doped with 14 TMs in Figure 4(a) are seen to be thermodynamically favored and indicates bonding as with the $3 \mathrm{NV}-\mathrm{CN}_{x} \mathrm{NT}$ case. The elucidated band structures again show that various electronic properties of $\mathrm{CN}_{x} \mathrm{NT}$-based devices are achievable.

3.5. Magnetic Properties. On the other hand, we also evaluate the effects of TM adsorption on the magnetic properties of 


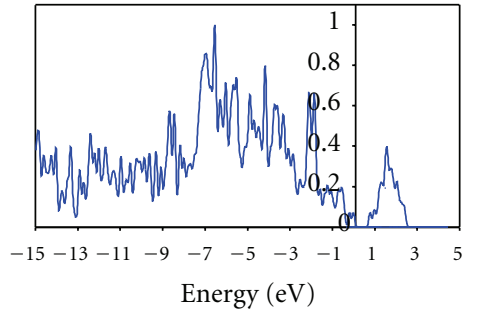

(a) Pure- $\mathrm{C}_{100}(10,0)$

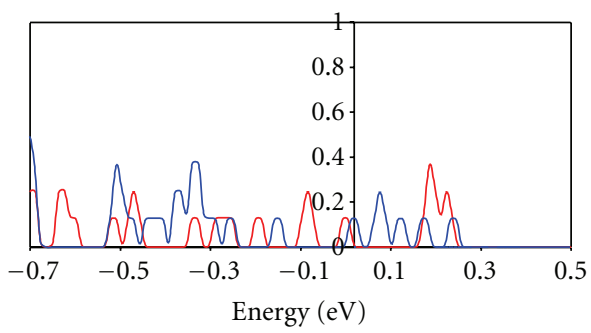

- Monovacancy

- $3 \mathrm{NV}-\mathrm{CN}_{x} \mathrm{NT}$

(d) Monovacancy- $\mathrm{C}_{119}(10,0), 3 \mathrm{NV}-\mathrm{CNT}\left(\mathrm{C}_{116} \mathrm{~N}_{3}\right)$

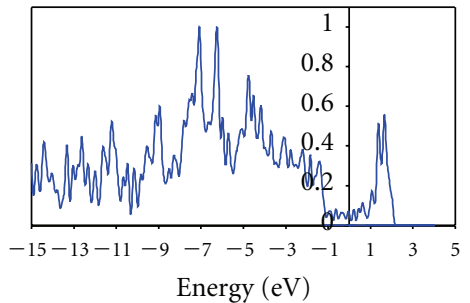

Energy $(\mathrm{eV})$

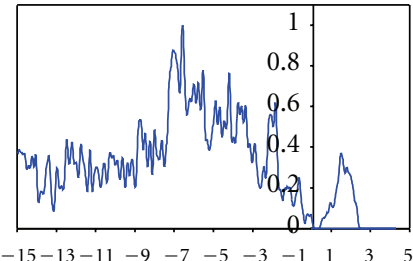

Energy $(\mathrm{eV})$

(b) Low doped- $\mathrm{C}_{119} \mathrm{~N}_{1}(10,0)$

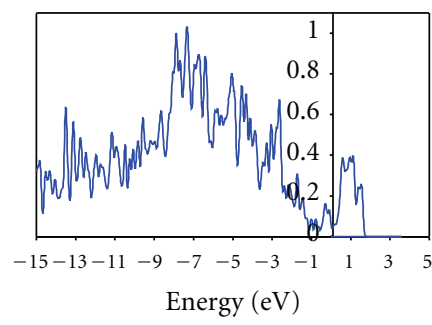

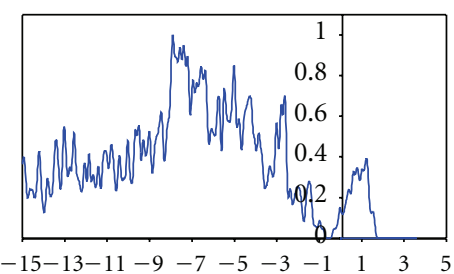

Energy $(\mathrm{eV})$

(c) High doped- $\mathrm{C}_{118} \mathrm{~N}_{2}(10,0)$

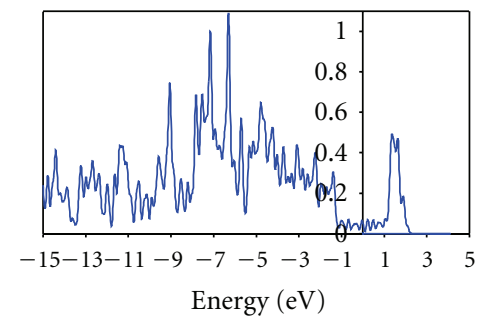

(e) NS5 at $3.33 \%$

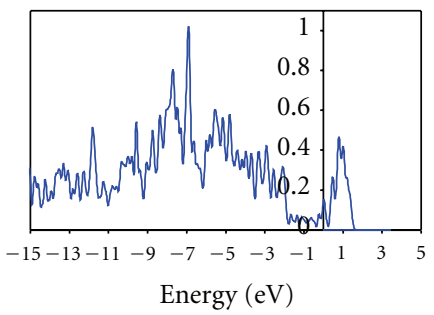

(h) High doped- $\mathrm{C}_{98} \mathrm{~N}_{2}(5,5)$

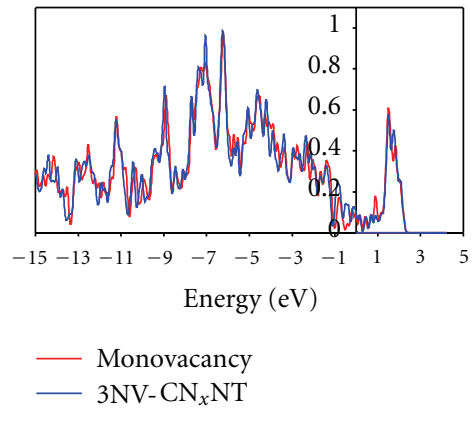

(i) Monovacancy-C $99(5, \quad 5), \quad 3 \mathrm{NV}-$ $\mathrm{CNT}\left(\mathrm{C}_{96} \mathrm{~N}_{3}\right)$

FIGURE 7: Total density of states (TDOS) of (a) pristine (10,0) nanotube, (b) low-doped nitrogen substitution $\mathrm{C}_{119} \mathrm{~N}_{1}(10,0)$, (c) high-doped nitrogen substitution $\mathrm{C}_{118} \mathrm{~N}_{2}(10,0)$, (d) monovacancy $\mathrm{C}_{119}(10,0)$ and pyridine-like nitrogen doping $3 \mathrm{NV}-\mathrm{CNT} \mathrm{C}_{116} \mathrm{~N}_{3}$. (e) Nitrogen doping at $3.33 \%$ concentration for the NS5 configuration. TDOS of (f) pristine $(5,5)$ nanotube, $(\mathrm{g})$ low-doped nitrogen substitution $\mathrm{C}_{99} \mathrm{~N}_{1}$ $(5,5)$, (h) high-doped nitrogen substitution $\mathrm{C}_{98} \mathrm{~N}_{2}(5,5)$, (i) monovacancy $\mathrm{C}_{99}(5,5)$ and pyridine-like doping $3 \mathrm{NV}^{-} \mathrm{CNT}_{96} \mathrm{~N}_{3}$. TDOS of undoped tube with monovacancy is indicated by red curves. The Fermi level is at $0 \mathrm{eV}$, and smearing of $0.05 \mathrm{eV}$ was applied for all graphs.

the two $\mathrm{CN}_{x} \mathrm{NTs}$. We find that the net magnetic moment emerges, ranging from 2.28 (for V/3NV-CN $\mathrm{CN}_{x} \mathrm{NT}$ ) to $0 \mu_{\mathrm{B}}$ (for $\mathrm{Sc} /, \mathrm{Mn} /, \mathrm{Fe} /, \mathrm{Cu} /, \mathrm{Zn} /, \mathrm{Pd} /, \mathrm{Ag} /, \mathrm{Pt} /$ or $\mathrm{Au} / 3 \mathrm{NV}-\mathrm{CN}_{x} \mathrm{NTs}$ ) for the $(10,0)$ tube and from 2.54 (for $\left.\mathrm{V} / 3 \mathrm{NV}-\mathrm{CN}_{x} \mathrm{NT}\right)$ to 0 $\mu_{\mathrm{B}}$ (for $\mathrm{Sc} /, \mathrm{Mn} /, \mathrm{Fe} /, \mathrm{Cu} /, \mathrm{Zn} /, \mathrm{Pd} /, \mathrm{Ag} /, \mathrm{Pt} /$, or $\mathrm{Au} / 3 \mathrm{NV}-$ $\left.\mathrm{CN}_{x} \mathrm{NTs}\right)$ for the $(5,5)$ tube as shown in Table 2 . This is reasonable, because the ground states of the two $\mathrm{CN}_{x} \mathrm{NTs}$ are nonmagnetic, and the net spin magnetic moment mainly originates from the contributions of TMs.

\section{Conclusions}

The study successfully investigated the structural, electronic and magnetic properties of the nitrogenated $(5,5)$ and
$(10,0)$ nanotubes coupled with the chemical functionalization of nanotube with defects with 14 different TMs using the first-principles methods within the density functional theory formalism using mainly the spin-polarized calculations. Moreover, the study revealed the effects of different types of nitrogenation that have been elucidated from the band structures, by describing the density of states and molecular orbitals.

From the spin-polarized calculations, it indicated that the substitutional nitrogenation, converted the semiconducting $(10,0)$ nanotubes $(\sim 0.7 \mathrm{eV}$ band gap) into metallic. Furthermore, the study found that the electronic structures are dependent on the sites the nitrogen atoms occupy. Thus, the electronic properties may be controlled not only by the doping concentration but also by how the dopants are 

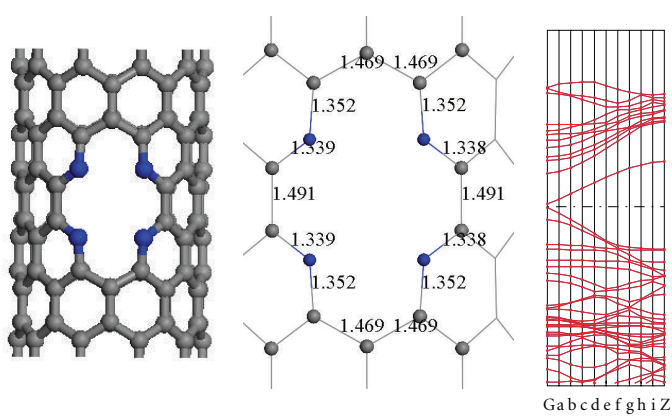

(a) $4 \mathrm{ND}-\mathrm{CN}_{x} \mathrm{NT}$

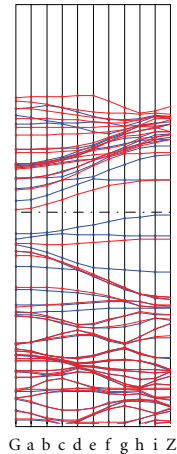

(d) V/4ND

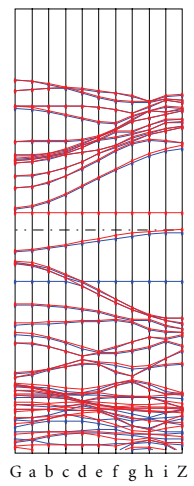

(j) $\mathrm{Cu} / 4 \mathrm{ND}$

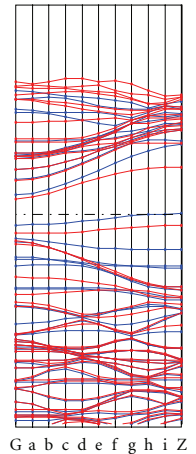

(e) $\mathrm{Cr} / 4 \mathrm{ND}$

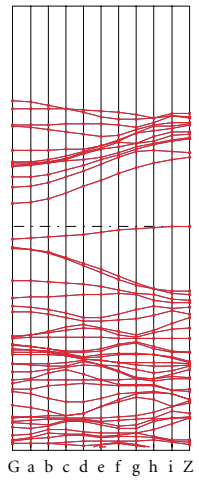

(k) $\mathrm{Zn} / 4 \mathrm{ND}$

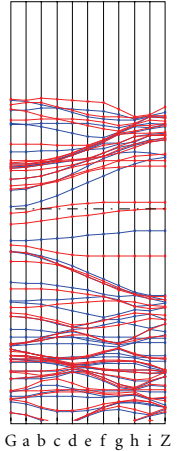

(f) $\mathrm{Mn} / 4 \mathrm{ND}$

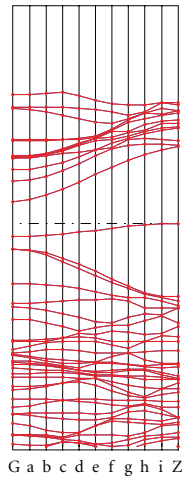

(1) $\mathrm{Pd} / 4 \mathrm{ND}$
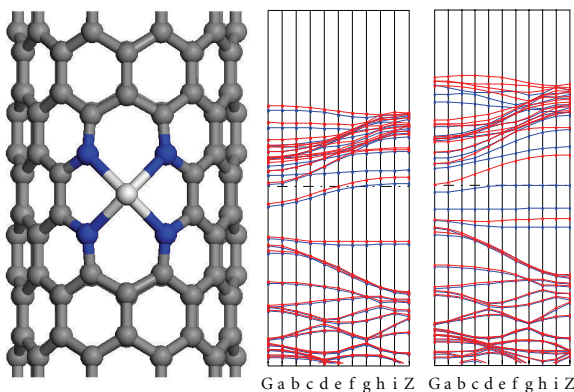

(b) Sc/4ND

(c) $\mathrm{Ti} / 4 \mathrm{ND}$

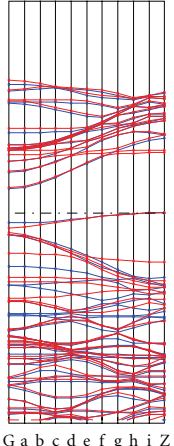

(g) $\mathrm{Fe} / 4 \mathrm{ND}$

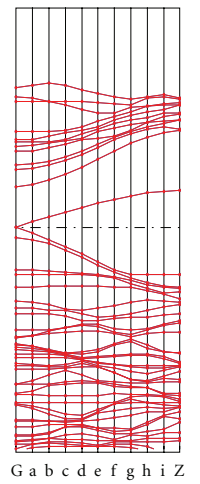

(m) $\mathrm{Ag} / 4 \mathrm{ND}$

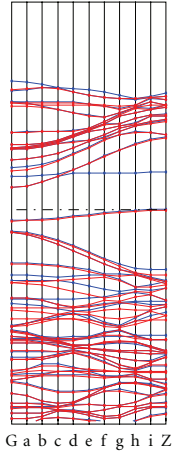

(h) $\mathrm{Co} / 4 \mathrm{ND}$

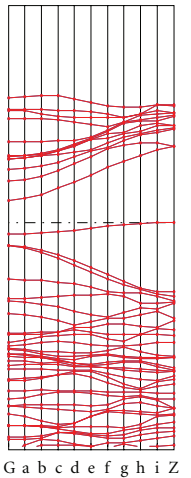

(n) $\mathrm{Pt} / 4 \mathrm{ND}$

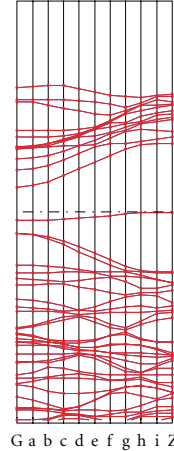

(i) $\mathrm{Ni} / 4 \mathrm{ND}$

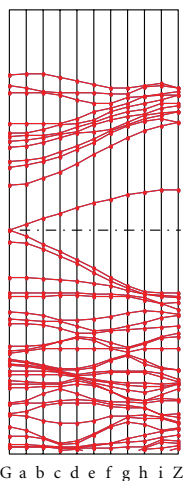

(o) $\mathrm{Au} / 4 \mathrm{ND}$

FIGURE 8: The geometrically optimized structure and bond lengths $(\AA)$ of N substitution into the carbon framework with the formation of porphyrine-like vacancy and band structures of 14 TMs adsorbed on $(10,0)$ zigzag $\mathrm{CN}_{x} \mathrm{NT}$ with porphyrine-like defect. The Fermi level is set as zero and plotted with a line. The blue and red plots denote alpha and beta band structures, respectively. Only one part indicates that this system is non-magnetic. Energies at the vertical axis are at arbitrary units.

positioned. For metallic $(5,5)$ nanotubes, the N-doping was shown to significantly enhance the state density at the vicinity of the Fermi level from which chemical activity was enhanced. The electronic and magnetic properties were effectively modified by the chemical functionalization of the TMs on the $(10,0)$ and $(5,5) 3 \mathrm{NV}-\mathrm{CN}_{x} \mathrm{NT}$ and $(10$, 0) $4 \mathrm{ND}-\mathrm{CN}_{x} \mathrm{NT}$. Combining all the results of the study, it demonstrated an interesting prospect of tailoring the properties of nanotubes through the introduction of imperfections. Through an appropriate introduction of dopants, defects and TMs, SWCNTS can be metallic, half metallic, or semiconducting $\mathrm{CN}_{x} \mathrm{NT}$ with variable band gaps.

\section{Acknowledgments}

This work was supported in part by the Department of Science and Technology, Philippine Council for Advanced Science and Technology Research and Development (DOST, PCASTRD), Philippine Council for Industry, Energy and 
Emerging Technology Research and Development (PCIEERD), and by the De La Salle University-Manila Faculty.

\section{References}

[1] D. Tasis, N. Tagmatarchis, A. Bianco, and M. Prato, "Chemistry of carbon nanotubes," Chemical Reviews, vol. 106, no. 3, pp. 1105-1136, 2006.

[2] Y. L. Zhao and J. F. Stoddart, "Noncovalent functionalization of single-walled carbon nanotubes," Accounts of Chemical Research, vol. 42, no. 8, pp. 1161-1171, 2009.

[3] V. N. Khabashesku, W. E. Billups, and J. L. Margrave, "Fluorination of single-wall carbon nanotubes and subsequent derivatization reactions," Accounts of Chemical Research, vol. 35, no. 12, pp. 1087-1095, 2002.

[4] S. Niyogi, M. A. Hamon, H. Hu et al., "Chemistry of singlewalled carbon nanotubes," Accounts of Chemical Research, vol. 35, no. 12, pp. 1105-1113, 2002.

[5] S. Banerjee, T. Hemraj-Benny, and S. S. Wong, "Covalent surface chemistry of single-walled carbon nanotubes," Advanced Materials, vol. 17, no. 1, pp. 17-29, 2005.

[6] D. A. Britz and A. N. Khlobystov, "Noncovalent interactions of molecules with single walled carbon nanotubes," Chemical Society Reviews, vol. 35, no. 7, pp. 637-659, 2006.

[7] R. Sen, B. C. Satishkumar, A. Govindaraj, K. R. Harikumar, M. K. Renganathan, and C. N. R. Rao, "Nitrogen-containing carbon nanotubes," Journal of Materials Chemistry, vol. 7, no. 12, pp. 2335-2337, 1997.

[8] M. Terrones, H. Terrones, N. Grobert et al., "Efficient route to large arrays of $\mathrm{CN}_{x}$ nanofibers by pyrolysis of ferrocene/melamine mixtures," Applied Physics Letters, vol. 75, no. 25, pp. 3932-3934, 1999.

[9] R. Czerw, M. Terrones, J. C. Charlier et al., "Identification of electron donor states in n-doped carbon nanotubes," Nano Letters, vol. 1, no. 9, pp. 457-460, 2001.

[10] M. Terrones, P. M. Ajayan, F. Banhart et al., "N-doping and coalescence of carbon nanotubes: synthesis and electronic properties," Applied Physics A, vol. 74, no. 3, pp. 355-361, 2002.

[11] D. Golberg, P. S. Dorozhkin, Y. Bando et al., "Structure, transport and field-emission properties of compound nanotubes: $\mathrm{CN}_{x}$ vs. $\mathrm{BNC}_{x}(x<0.1)$," Applied Physics A, vol. 76, no. 4, pp. 499-507, 2003.

[12] F. Villalpando-Páez, A. H. Romero, E. Muñoz-Sandoval, L. M. Martínez, H. Terrones, and M. Terrones, "Fabrication of vapor and gas sensors using films of aligned $\mathrm{CN}_{x}$ nanotubes," Chemical Physics Letters, vol. 386, no. 1-3, pp. 137-143, 2004.

[13] K. Suenaga, M. P. Johansson, N. Hellgren et al., "Carbon nitride nanotubulite-densely-packed and well-aligned tubular nanostructures," Chemical Physics Letters, vol. 300, no. 5-6, pp. 695-700, 1999.

[14] S. H. Lim, H. I. Elim, X. Y. Gao et al., "Electronic and optical properties of nitrogen-doped multiwalled carbon nanotubes," Physical Review B, vol. 73, no. 4, Article ID 045402, 6 pages, 2006.

[15] R. Droppa, C. T. M. Ribeiro, A. R. Zanatta, M. C. Dos Santos, and F. Alvarez, "Comprehensive spectroscopic study of nitrogenated carbon nanotubes," Physical Review B, vol. 69, no. 4, Article ID 045405, 9 pages, 2004.

[16] F. Villalpando-Paez, A. Zamudio, A. L. Elias et al., "Synthesis and characterization of long strands of nitrogen-doped singlewalled carbon nanotubes," Chemical Physics Letters, vol. 424, no. 4-6, pp. 345-352, 2006.
[17] S. S. Yu, Q. B. Wen, W. T. Zheng, and Q. Jiang, "Effects of doping nitrogen atoms on the structure and electronic properties of zigzag single-walled carbon nanotubes through first-principles calculations," Nanotechnology, vol. 18, no. 16, Article ID 165702, 2007.

[18] L. Qiao, W. T. Zheng, H. Xu, L. Zhang, and Q. Jiang, "Field emission properties of $\mathrm{N}$-doped capped single-walled carbon nanotubes: a first-principles density-functional study," The Journal of Chemical Physics, vol. 126, no. 16, Article ID 164702, 7 pages, 2007.

[19] Y.-S. Min, E. J. Bae, U. J. Kim et al., "Unusual transport characteristics of nitrogen-doped single-walled carbon nanotubes," Applied Physics Letters, vol. 93, no. 4, Article ID 043113, 3 pages, 2008.

[20] A. R. Rocha, M. Rossi, A. Fazzio, and A. J. R. Da Silva, "Designing real nanotube-based gas sensors," Physical Review Letters, vol. 100, no. 17, Article ID 176803, 4 pages, 2008.

[21] Y. F. Li, Z. Zhou, and L. B. Wang, " $\mathrm{CN}_{x}$ nanotubes with pyridinelike structures: p-type semiconductors and Li storage materials," The Journal of Chemical Physics, vol. 129, no. 10, Article ID 104703, 5 pages, 2008.

[22] K. Gong, F. Du, Z. Xia, M. Durstock, and L. Dai, "Nitrogendoped carbon nanotube arrays with high electrocatalytic activity for oxygen reduction," Science, vol. 323, no. 5915, pp. 760-764, 2009.

[23] P. Ayala, R. Arenal, M. Rümmeli, A. Rubio, and T. Pichler, "The doping of carbon nanotubes with nitrogen and their potential applications," Carbon, vol. 48, no. 3, pp. 575-586, 2010.

[24] H. Yoon, S. Ko, and J. Jang, "Nitrogen-doped magnetic carbon nanoparticles as catalyst supports for efficient recovery and recycling," Chemical Communications, no. 14, pp. 1468-1470, 2007.

[25] Y. Shao, J. Sui, G. Yin, and Y. Gao, "Nitrogen-doped carbon nanostructures and their composites as catalytic materials for proton exchange membrane fuel cell," Applied Catalysis B, vol. 79, no. 1, pp. 89-99, 2008.

[26] F. B. Su, Z. Q. Tian, C. K. Poh et al., Chemistry of Materials, vol. 27, 832 pages, 2010.

[27] X. Li, S. Park, and B. N. Popov, "Highly stable Pt and PtPd hybrid catalysts supported on a nitrogen-modified carbon composite for fuel cell application," Journal of Power Sources, vol. 195, no. 2, pp. 445-452, 2010.

[28] Y. Shao, J. Liu, Y. Wang, and Y. Lin, "Novel catalyst support materials for PEM fuel cells: current status and future prospects," Journal of Materials Chemistry, vol. 19, no. 1, pp. 46-59, 2009.

[29] S. Jiang, Y. Ma, G. Jian et al., "Facile construction of Pt$\mathrm{Co} / \mathrm{CN}_{x}$ nanotube electrocatalysts and their application to the oxygen reduction reaction," Advanced Materials, vol. 21, no. 48, pp. 4953-4956, 2009.

[30] Y. Zhou, R. Pasquarelli, T. Holme, J. Berry, D. Ginley, and R. O'Hayre, "Improving PEM fuel cell catalyst activity and durability using nitrogen-doped carbon supports: observations from model Pt/HOPG systems," Journal of Materials Chemistry, vol. 19, no. 42, pp. 7830-7838, 2009.

[31] G. G. Wildgoose, C. E. Banks, and R. G. Compton, "Metal nanoparticles and related materials supported on Carbon nanotubes: methods and applications," Small, vol. 2, no. 2, pp. 182-193, 2006.

[32] V. Georgakilas, D. Gournis, V. Tzitzios, L. Pasquato, D. M. Guldi, and M. Prato, "Decorating carbon nanotubes with metal or semiconductor nanoparticles," Journal of Materials Chemistry, vol. 17, no. 26, pp. 2679-2694, 2007. 
[33] R. J. White, R. Luque, V. L. Budarin, J. H. Clark, and D. J. MacQuarrie, "Supported metal nanoparticles on porous materials. Methods and applications," Chemical Society Reviews, vol. 38, no. 2, pp. 481-494, 2009.

[34] B. Yue, Y. Ma, H. Tao et al., " $\mathrm{CN}_{x}$ nanotubes as catalyst support to immobilize platinum nanoparticles for methanol oxidation," Journal of Materials Chemistry, vol. 18, no. 15, pp. 1747-1750, 2008.

[35] X. Lepró, E. Terrés, Y. Vega-Cantú et al., "Efficient anchorage of Pt clusters on $\mathrm{N}$-doped carbon nanotubes and their catalytic activity," Chemical Physics Letters, vol. 463, no. 1-3, pp. 124129, 2008.

[36] Z. Chen, D. Higgins, H. Tao, R. S. Hsu, and Z. Chen, "Highly active nitrogen-doped carbon nanotubes for oxygen reduction reaction in fuel cell applications," Journal of Physical Chemistry C, vol. 113, no. 49, pp. 21008-21013, 2009.

[37] A. Z. Sadek, C. Zhang, Z. Hu et al., "Uniformly dispersed $\mathrm{Pt}-\mathrm{Ni}$ nanoparticles on nitrogen-doped carbon nanotubes for hydrogen sensing," Journal of Physical Chemistry C, vol. 114, no. 1, pp. 238-242, 2010.

[38] S. H. Yang, W. H. Shin, J. W. Lee, H. S. Kim, J. K. Kang, and Y. K. Kim, "Nitrogen-mediated fabrication of transition metalcarbon nanotube hybrid materials," Applied Physics Letters, vol. 90, no. 1, Article ID 013103, 3 pages, 2007.

[39] Y.-H. Li, T.-H. Hung, and C.-W. Chen, "A first-principles study of nitrogen- and boron-assisted platinum adsorption on carbon nanotubes," Carbon, vol. 47, no. 3, pp. 850-855, 2009.

[40] H. Feng, J. Ma, and Z. Hu, "Nitrogen-doped carbon nanotubes functionalized by transition metal atoms: a density functional study," Journal of Materials Chemistry, vol. 20, no. 9, pp. 17021708, 2010.

[41] M. Mananghaya, "Carbon Nanotubes Doped with Nitrogen, Pyridine-Like Nitrogen Defects and Transition Metal Atoms," Journal of Korean Chemical Society, vol. 56, no. 1, pp. 34-46, 2012.

[42] W. An and C. H. Turner, "Chemisorption of transition-metal atoms on boron- and nitrogen-doped carbon nanotubes: energetics and geometric and electronic structures," Journal of Physical Chemistry C, vol. 113, no. 17, pp. 7069-7078, 2009.

[43] S. R. Stoyanov, A. V. Titov, and P. Král, "Transition metal and nitrogen doped carbon nanostructures," Coordination Chemistry Reviews, vol. 253, no. 23-24, pp. 2852-2871, 2009.

[44] B. Delley, "An all-electron numerical method for solving the local density functional for polyatomic molecules," The Journal of Chemical Physics, vol. 92, no. 1, pp. 508-517, 1990.

[45] J. P. Perdew, K. Burke, and M. Ernzerhof, "Generalized gradient approximation made simple," Physical Review Letters, vol. 77, no. 18, pp. 3865-3868, 1996.

[46] B. Delley, "A scattering theoretic approach to scalar relativistic corrections on bonding," International Journal of Quantum Chemistry, vol. 69, no. 3, pp. 423-433, 1998.

[47] H. J. Monkhorst and J. D. Pack, "Special points for Brillouinzone integrations," Physical Review B, vol. 13, no. 12, pp. 5188 5192, 1976.

[48] C. L. Sun, H. W. Wang, M. Hayashi, L. C. Chen, and K. H. Chen, "Atomic-scale deformation in N-doped carbon nanotubes," Journal of the American Chemical Society, vol. 128, no. 26, pp. 8368-8369, 2006.

[49] H. C. Choi, S. Y. Bae, J. Park et al., "Experimental and theoretical studies on the structure of N-doped carbon nanotubes: possibility of intercalated molecular $\mathrm{N}_{2}$," Applied Physics Letters, vol. 85, no. 23, pp. 5742-5744, 2004.

[50] M. Terrones, R. Kamalakaran, T. Seeger, and M. Ruhle, "Novel nanoscale gas containers: encapsulation of $\mathrm{N}_{2}$ in $\mathrm{CN}_{x}$ nanotubes," Chemical Communications, no. 23, pp. 23352336, 2000.

[51] E. Durgun, S. Dag, V. M. K. Bagci, O. Gülseren, T. Yildirim, and S. Ciraci, "Systematic study of adsorption of single atoms on a carbon nanotube," Physical Review B, vol. 67, no. 20, Article ID 201401, 4 pages, 2003.

[52] E. Durgun, S. Dag, S. Ciraci, and O. Gülseren, "Energetics and electronic structures of individual atoms adsorbed on carbon nanotubes," Journal of Physical Chemistry B, vol. 108, no. 2, pp. 575-582, 2004.

[53] J. Zhao, H. Park, J. Han, and J. P. Lu, "Electronic properties of carbon nanotubes with covalent sidewall functionalization," Journal of Physical Chemistry B, vol. 108, no. 14, pp. 42274230, 2004.

[54] K. Kong, S. Han, and J. Ihm, Physical Review B, vol. 60, p. 6074, 1999.

[55] F. L. Hirshfeld, Theorefica Chimica Acta, vol. 44, p. 129, 1997. 

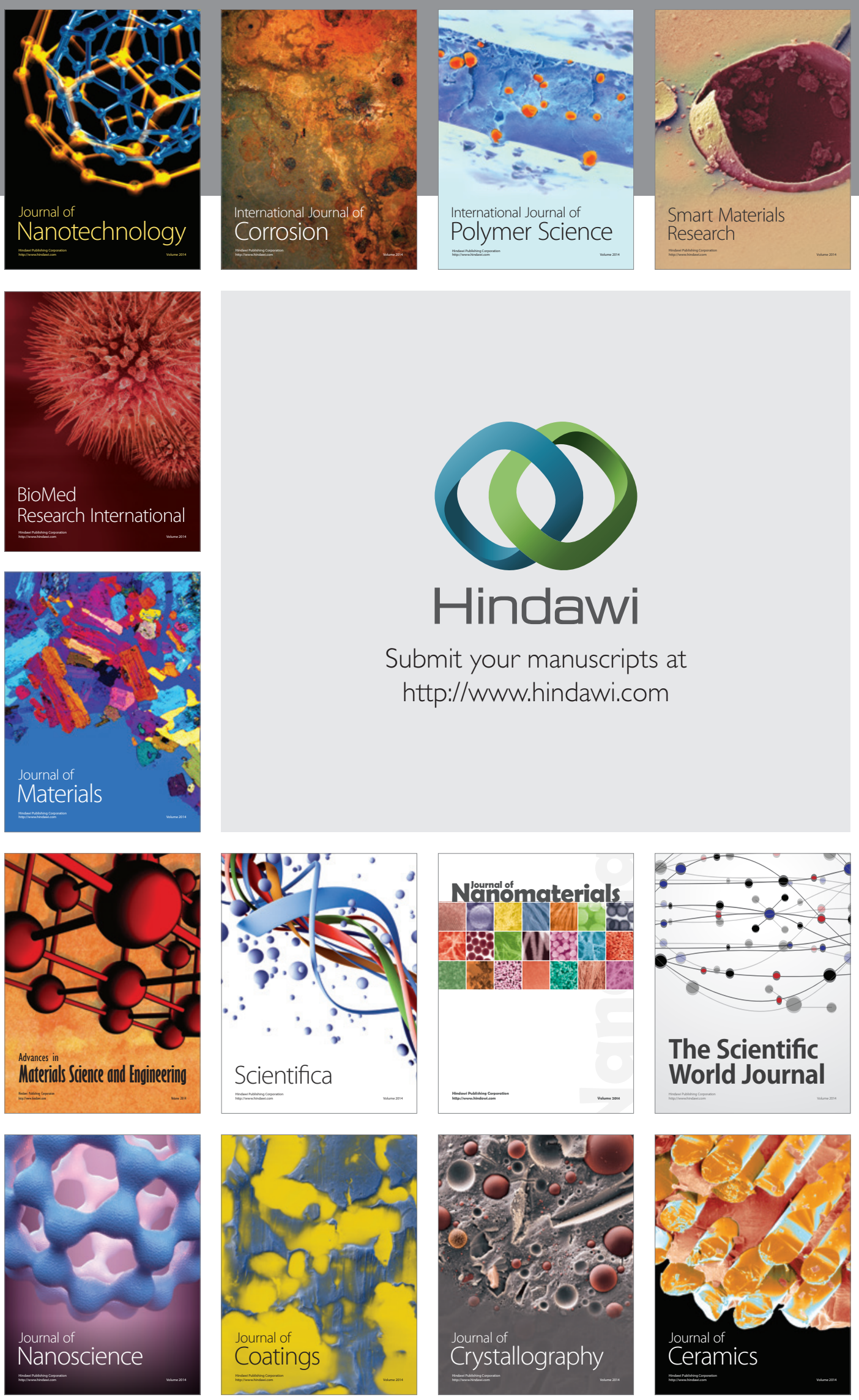

The Scientific World Journal

Submit your manuscripts at

http://www.hindawi.com

\section{World Journal}

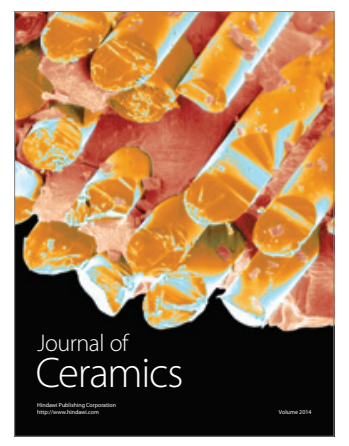

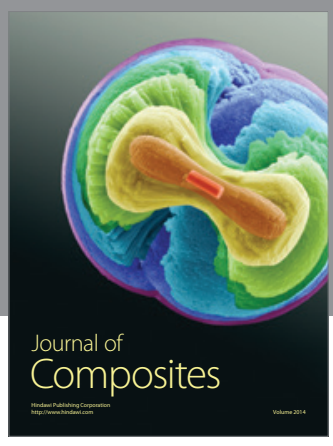
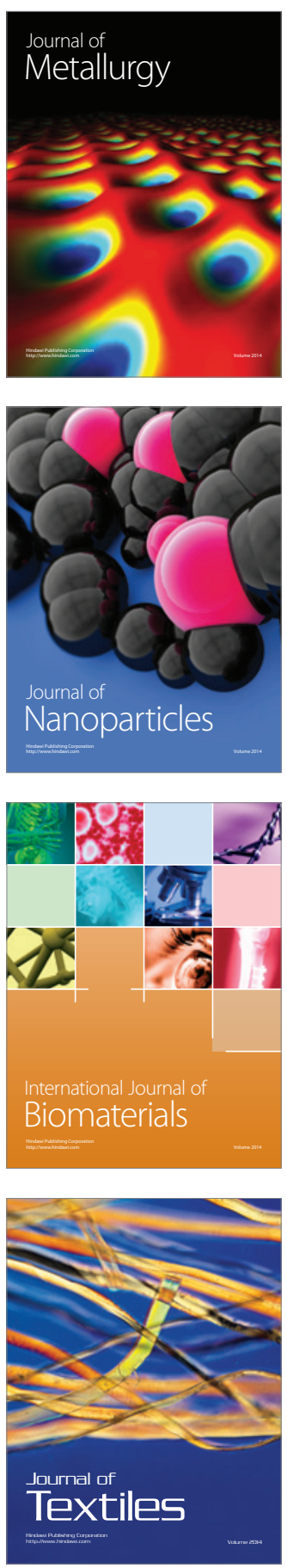